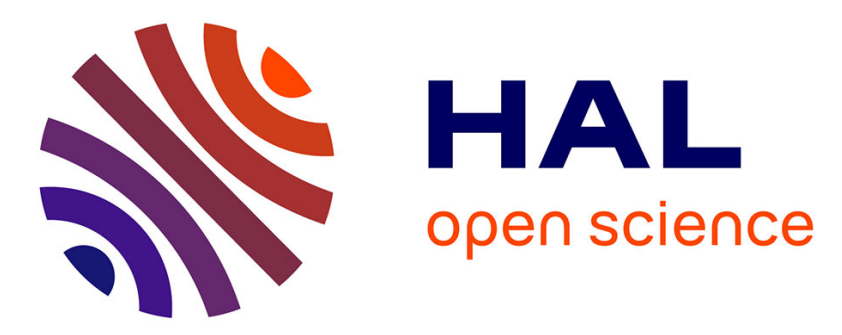

\title{
Influence of Seasonal River Discharge on Tidal Propagation in the Ganges-Brahmaputra-Meghna Delta, Bangladesh
}

\author{
M. W E Elahi, I. Jalón-rojas, X. H Wang, E. A Ritchie
}

\section{- To cite this version:}

M. W E Elahi, I. Jalón-rojas, X. H Wang, E. A Ritchie. Influence of Seasonal River Discharge on Tidal Propagation in the Ganges-Brahmaputra-Meghna Delta, Bangladesh. Journal of Geophysical Research. Oceans, 2020, 125 (11), pp.e2020JC016417. 10.1029/2020JC016417 . hal-03438903

\section{HAL Id: hal-03438903 https://hal.science/hal-03438903}

Submitted on 30 Nov 2021

HAL is a multi-disciplinary open access archive for the deposit and dissemination of scientific research documents, whether they are published or not. The documents may come from teaching and research institutions in France or abroad, or from public or private research centers.
L'archive ouverte pluridisciplinaire HAL, est destinée au dépôt et à la diffusion de documents scientifiques de niveau recherche, publiés ou non, émanant des établissements d'enseignement et de recherche français ou étrangers, des laboratoires publics ou privés. 
ELAHI MD WASIF E (Orcid ID: 0000-0002-9809-0037)

Jalón-Rojas Isabel (Orcid ID: 0000-0003-4254-4084)

Wang Xiao Hua (Orcid ID: 0000-0002-1774-6189)

\title{
Influence of seasonal river discharge on tidal propagation in the Ganges- Brahmaputra-Meghna Delta, Bangladesh
}

\author{
M. W. E. Elahi ${ }^{1,2}$, I. Jalón-Rojas ${ }^{3,2}$, X. H. Wang ${ }^{1,2}$ and E. A. Ritchie ${ }^{2}$
}

${ }^{1}$ The Sino-Australian Research Consortium for Coastal Management, UNSW Canberra, Canberra, ACT, Australia.

${ }^{2}$ School of Science, UNSW Canberra, Canberra, ACT, Australia

${ }^{3}$ UMR5805 EPOC, CNRS, OASU, University of Bordeaux, Pessac, France

Corresponding author: Md Wasif E Elahi (m.elahi@student.adfa.edu.au)

\section{Key Points:}

- The balance between tidal dissipation and generation depends on the residual velocity generated by river-tide interactions

- High amplitude of friction does not generate high quarterdiurnal tides always

- A critical river discharge determines the maximal generation of quarterdiurnal tides

\begin{abstract}
Significant research efforts have been devoted to understanding river-tide interactions in estuaries. However, studies on the impact of monsoon-driven fluctuations of river discharge are limited. Here, the role of varying river discharge on the tidal propagation and tidal limit along the Ganges-Brahmaputra-Meghna delta (GBMD), a macrotidal estuary subject to seasonal and annual river discharge variations, is investigated. The Delft3D hydrodynamic model is validated and applied to an average flood year condition and nine idealized scenarios covering the typical hydrological conditions. Results reveal that the upper limit of the tidal propagation shifts $75 \mathrm{~km}$ upstream during the dry season. The residual water level slope and tidal damping rate increase with river discharge beyond $100 \mathrm{~km}$ from the estuary mouth. The balance between the generation and dissipation of quarterdiurnal tides shifts spatially as a result of changes in channel convergence and friction, and temporally as a function of river discharge, which controls the total friction in the upper tidal river. The balance between tidal dissipation and generation depends on the residual velocity generated by river discharge and the velocity of the principal tides. The maximal generation of quarterdiurnal tides in the upper GBMD depends on the friction generated from the river-tide interaction. Critical river discharge thresholds produce an optimal condition of dissipation of semidiurnal tides and generation of

This article has been accepted for publication and undergone full peer review but has not been through the copyediting, typesetting, pagination and proofreading process which may lead to differences between this version and the Version of Record. Please cite this article as doi: 10.1029/2020JC016417
\end{abstract}


quarterdiurnal tides through friction at the upper and middle estuary. River discharge above the critical river discharge amount more rapidly dissipates both semidiurnal and quarterdiurnal tides than generates quarterdiurnal tides from nonlinear interactions.

\section{Introduction}

Knowledge of tidal wave propagation and tidal properties is essential to understand issues such as sediment transport, pollutants dispersion, morphological changes, and nutrient balances in estuarine and deltaic environments (e.g., Dalrymple and Choi, 2007; Ogston et al., 2017). Tides are also an important component in the assessment of flooding and submergence risks in shallow systems. Evaluating and understanding tides in the upper reaches of tidal rivers is particularly challenging, because the balance of bottom friction, channel geometry and river flow results in non-linear and non-stationary tides (Savenije et al., 2008; Cai et al., 2014; Guo et al., 2015; Cai et al., 2019). River flow modulates tidal propagation in the estuary by damping the tidal amplitudes and transforming energy from the principal tides to overtides. For example, the tidal range can be 1.7 and 7.5 times higher during dry periods than wet periods in the upper Yangzte (Guo et al., 2015) and Gironde (Jalón-Rojas et al. 2018) estuaries, respectively. Influence of seasonal variations of river flow on tides are also found in the Guadalquivir (Wang et al., 2014) and St. Lawrence estuaries ( Matte, et al. , 2017). Cai et al (2019) shows that the increase of river discharge beyond a critical amount reduces the tidal damping in the upper part of the Yangtze river. River tide properties can thus vary in systems subject to strong fluctuations of river discharge, such as tropical monsoon estuaries. However, river tides in this type of environment are still poorly understood.

The Ganges-Brahmaputra-Meghna Delta (GBMD, Bangladesh) provides an ideal example to investigate river tides dynamics subject to monsoon variability. It contains a large network of rivers, tidal creeks, waterway inlets, which, along with the complex coastline geometry, results in complex hydrodynamic processes. The GBMD is a shallow system, highly susceptible to increased total water level elevations resulting from the combined effects of increased storm surge, wave-induced setup, and astronomical tides that occur during the landfall of severe cyclones (Pethick \& Orford, 2013; Tazkia et al. 2017). In recent decades, storm-surges associated with severe cyclones have increased, leading to an increase in the probability of higher and wider spread flooding in the near shore and shallow areas of

the GBMD. Importantly, the GBMD also experiences high interannual and seasonal variability of river flow linked with monsoon variability that may affect tidal propagation and properties (Bricheno and Wolf, 2018). Increased understanding of tides in the GBMD delta in connection with river flow is therefore crucial for a proper disaster management plan and maintenance in this complex region.

As with other estuarine systems, previous numerical studies have shown that tidal propagation is controlled by a combination of geometrical shape of channel, bathymetry, bottom friction, and river discharge. Bricheno et al. (2016) showed that tides cannot travel beyond the confluence of the Ganges and Brahmaputra due to the forcing of river discharge on tide. Rose and Bhaskaran (2017) reported that there is marginal amplification of the diurnal tide and nearly double amplification of the semi-diurnal tides in the Meghna delta compared to the eastern and western coast of the GBMD. All of these previous model studies largely disagree with the tidal range observations by the Bangladesh Water Development 
Board (BWDB), particularly in the upper part of the GBMD due to a lack of accurate bathymetry and complex channel network of the estuary in the models (Krien et al. 2016). Although most of these studies note the importance of river discharge on tide, no study has accurately modelled and evaluated the influence of river discharge on tidal propagation in the GBMD. Furthermore, physical processes controlling the seasonal variability of the M2 (semidiurnal) tide and other main tidal constituents in the GBMD are still poorly understood. Lack of hourly tidal water level stations along the GBMD also explain this research gap and the need to implement numerical studies in the system.

This study establishes a validated numerical model setup that reproduces the tidal properties of the GBMD and uses it to investigate the modulation of tides along the GBMD due to seasonal river discharge variations. Numerical simulations are implemented for real and idealized scenarios of river discharge using the Delft-3D numerical model. The model setup is validated for a combination of three stations located in the exposed coast and six stations along the upper estuary. Stationary and non-stationary harmonic analysis methods are used to evaluate the influence of river discharge on tidal constituents. The structure of the paper is as follows. Section 2 describes the main characteristic of the study site. Water level and river flow observations, the model setup and tidal analysis methods are detailed in Section 3. Results and discussion are presented in Section 4 including the spatial and temporal variations of tidal constituents for different hydrological years and different discharge scenarios. A summary and conclusions are presented in Section 5.

\section{Study Site}

Located in the lower part of Bangladesh, the Ganges-Brahmaputra-Meghna Delta has a $710-\mathrm{km}$ coastline and covers $32 \%$ of the country's total geographical area of 147,570 square $\mathrm{km}$ (Fig. 1a). Numerous rivers, streams, and canals combine to make up $22 \%$ of the GBMD area. With an average annual freshwater discharge of $40,000 \mathrm{~m}^{3} \mathrm{~s}^{-1}$, the GBMD is the third largest coastal river system discharge worldwide. These waterways are seasonal and reach their maximum capacity during the monsoon season. The Ganges and Brahmaputra rivers merge with the Meghna river in central Bangladesh, conveying $80 \%$ of the total river discharge from the upper catchment area through the GBMD towards the Bay of Bengal (BoB).

The river discharge of these three rivers is subject to high seasonal variability (e.g., BWDB, 2012). The Brahmaputra river discharge starts increasing in the early monsoon period (June-July) and reaches its first peak in the third week of July. It then falls and rises again and attains a second peak in the first week of August. The Ganges river has two peaks: one in the third week of July; and one in the second week of September. The first flood peak in the Upper Meghna typically occurs in the second or third week of May. In general, there is a total annual river discharge inflow into the GBMD from India of 1,110.6 $\mathrm{km}^{3}$ (FAO, 2016). The high river discharge and its seasonal variations also modulate river salinity in the GBMD. During low river discharge periods, the river water salinity increases up to 5 PSU between $30-40 \mathrm{~km}$ from the river mouth whereas the river water salinity is zero at the river mouth during high river discharge periods (Bricheno and Wolf, 2018).

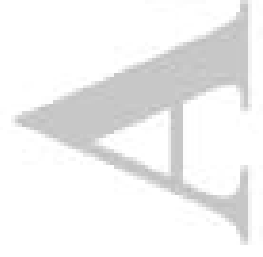



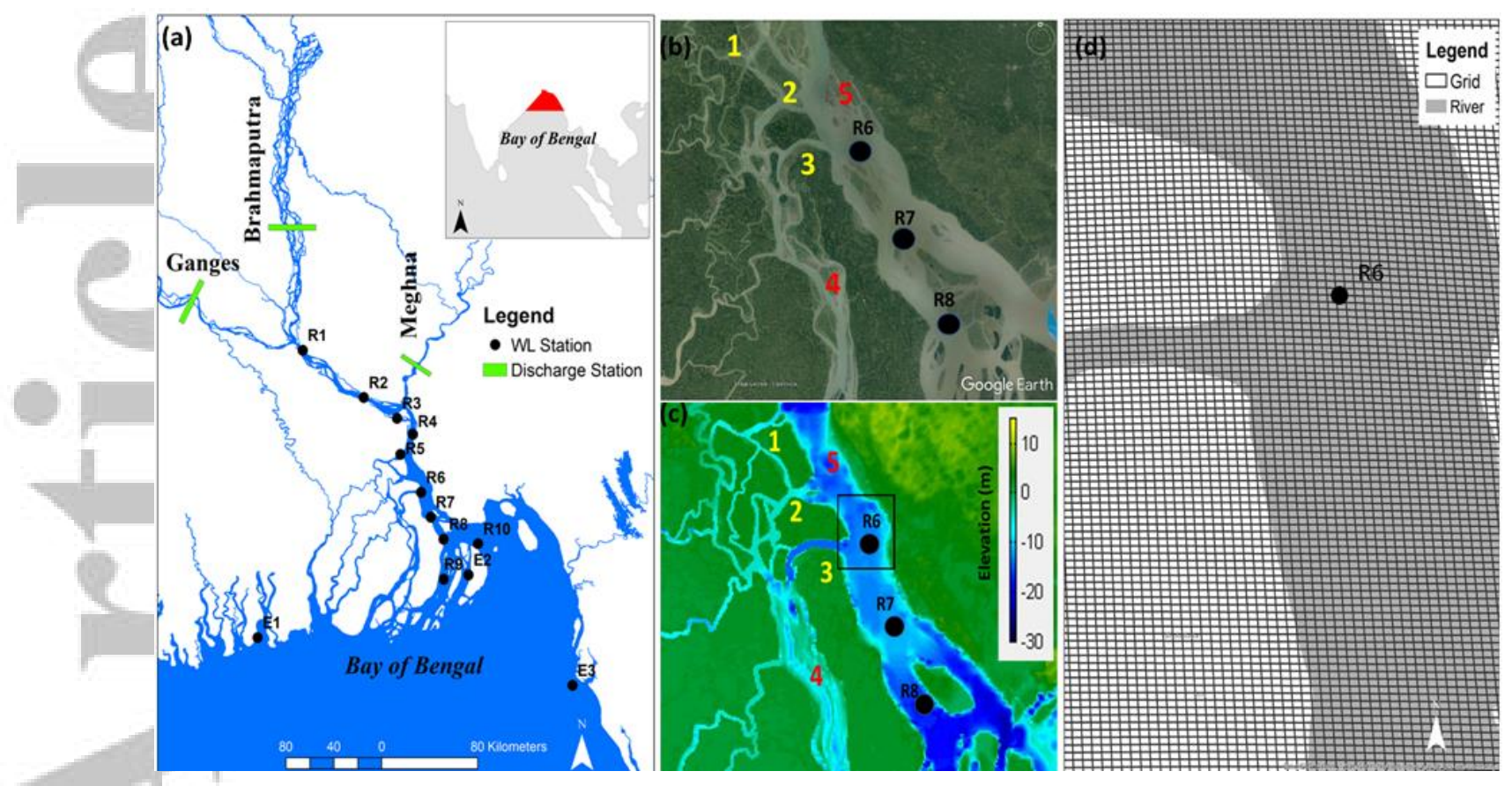

Figure 1. (a) Location of the study area; E1-E3 are stations located on the exposed coast and R1-R9 are stations located along the river. (b) the complex channel network in the lower Meghna river; 1-3 (yellow) represent split channels and 4-5 (red) denote examples of shallow land; (c) model bathymetry at the lower Meghna; 0 m denotes mean sea level and (d) zoomed view of the model grid at R6 within the black square area indicated in Fig. 1c.

The Meghna estuary entry into the BoB is divided into a series of extensive shoals including the Meghna flats, mud flats, and estuarine islands (Figure 1b, Google, n.d.). The presence of isolated shoals along the GBMD with depths up to $5.5 \mathrm{~m}$ makes the hydrodynamic properties of the estuary more complex compared to other estuaries (Snead, 2010). The river morphology of the GBMD is very dynamic as the delta is relatively flat and it is scoured by deep river channels (Bricheno et al., 2016). In particular, the high river flow during the monsoon has a significant influence on the sediment transportation along the GBMD. According to Allison (1998), the cohesive sediments of the GBMD are very mobile, and the position and geometry of the river channels are constantly changing year to year with net gains of $14.8 \mathrm{~km}^{2}$ between 1840 and 1972, and of $4.4 \mathrm{~km}^{2}$ between 1840 and 1984 . 
Tides along the GBMD are semi-diurnal. The mean tidal range varies from 3 to $6 \mathrm{~m}$ along the Bangladesh coast with the highest tidal range located just east of the Lower Meghna estuary (Haque and Nicholls, 2018). Coastal flooding from tides is common in the central and western estuaries of the Bangladesh coast. In the 1960s, 123 polders were constructed by the Coastal Embank Project in the southwest coastal region of Bangladesh to protect agricultural land from tidal flooding. This reduced the tidal floodplain area resulting in increased water levels from silted riverbeds and amplifying the influence of the tides. The tidal ranges vary from 2-4 $\mathrm{m}$ along the GBMD and funnel-shaped estuaries cause local tidal amplification up to $100 \mathrm{~km}$ inland of the delta (Rogers and Goodbred 2014).

\section{Data and Methods}

3.1 In situ observations of water level and river discharge

This work is based on three sets of data:

i. Hourly water level data at three stations located on the exposed coast (Fig. 1a, E1-E3): Hironpoint (E1, 1977-2003), Charchanga (E2, 1980-2000), and Cox's bazar (E3, 1983-2006). These data were provided by the Bangladesh Inland Water Transport Authority (BIWTA).

ii. Water level data at ten stations along the GBMD (Fig. 1b, R1-R10). Baruriatransit (R1) and Mawa station (R2) record daily mean water level measurement. The rest of the stations record daily maximum and minimum water level measurement. Data are available from 1983 to 2012. The specific years of data availability are different for each station. These data were supplied by the BWDB.

iii. Daily river discharge at three stations (Fig. 1a): Hardinge Bridge (in Brahmaputra river); Bahadurabad (in Ganges river); and Bhairab Bazar (Meghna river). Discharge data are available from 1996 to 2012. The data contain discontinuities that vary for each station. Records were provided by the BWDB authority.

\subsection{Numerical model setup}

The two-dimensional Delft-3D-Flow numerical model (Delft3D 3.28.50.01) is used to simulate the water level and current velocity in the GBMD. This model calculates nonsteady flow and transport phenomena. The Flow module solves the Reynold's equations for an incompressible fluid under shallow water and Boussinesq assumptions. The set of partial differential equations, initial and boundary conditions are solved on a finite difference grid. Detail of the equations and numerical aspects can be found in the Delft 3D flow user manual (Deltares, 2014). The model is applied with a single-layer sigma-coordinate system in vertical and a curvilinear grid for spatial discretization in horizontal. Due to the funnel shape of the Bay of Bengal coastline, the outer boundary of the grid is funnel shaped with varying grid resolution (Figure 1a). The grid resolution varies from $1320 \mathrm{~m}$ x $956 \mathrm{~m}$ in the ocean to $300 \mathrm{~m}$ x $200 \mathrm{~m}$ in rivers. Figure 1d shows a zoom view of the grid resolution at R6 and demonstrates that the grid resolution can accurately represent the complex channel bathymetry of the GBMD. Time series of observed river discharge (Section 3.1) are specified as the upstream boundary conditions. Astronomical constituents for the water level at downstream locations 
are generated by applying Delft Dashboard, which uses the TPXO 7.2 Global Inverse Tide Model.

The bathymetry of the rivers and estuaries is specified by using measured cross sections collected during year 2007 to 2014 within the ESPA-delta project of the Bangladesh University of Engineering and Technology (BUET). The inland ground elevation data were collected by the Centre for Environmental and Geographic Information Services (CEGIS), Bangladesh, which was generated from the FINNMAP (a Finland based private organization) Land Survey 1991, National Digital Elevation Model (DEM) from Floodplain Action Plan-19 (FAP19). The ocean bathymetry is specified using open access data from the General Bathymetric Chart of the Oceans (GEBCO, http://www.gebco.net/). The model was calibrated by applying different combinations of Manning's coefficient and then comparing modelled and observed water level at E1, E2, E3 and R3 stations. An increasing roughness parameter from 0.00025 (sea) to 0.05 (upper estuary) provided the best reproduction of observations. A full validation analysis is detailed in Section 4.1.

The model is applied to an average flood year and nine idealized scenarios. The average flood year is selected based on BWDB (2012), which categorized historical flood events from 1954 to 2012 according to: wet years (flooded area > 24\%); average flood years (flooded area 20-24\%); and dry years (flooded area $<20 \%$ ). The model setup is validated for the average flooding year (2000), which has a large amount of water level data, and then applied to the idealized scenarios covering the typical hydrological conditions of the system, from zero to $125,000 \mathrm{~m}^{3} \mathrm{~s}^{-1}$.

\subsection{Tide analysis method}

Water level and current velocities are numerically simulated at R1-R10 (Figure 1a) and analysed using four methods: tidal height analysis; stationary harmonic analysis; nonstationary harmonic analysis based on wavelet approach; and computation of the total friction from the subtidal decomposition of current velocities.

\section{- Tidal height analysis}

Water level variations along the Meghna estuary are first plotted together with river discharge to gain insight into the influence of river discharge and tide. The tidal range for each station is calculated as the difference between daily high water and low water level.

\section{Stationary harmonic analysis}

The stationary harmonic analysis of water level time series at all stations (R1-R10) are performed using T_TIDE (Pawlowicz et al., 2002). This method computes the time average amplitude A and phase $\Phi$ of different tidal species. However, T_TIDE cannot provide the time varying amplitude and phase of tidal constituents. Details of the T_TIDE tool can be found in Pawlowicz et al. (2002).

\section{- Non-stationary harmonic analysis}

To assess the seasonal variations of the tidal constituents in the GBMD, a nonstationary harmonic analysis based on the Complex Demodulation method (Bloomfield, 2004 ) is applied to water level time series. In particular, the temporal variation of the amplitudes and phases of the semidiurnal and quarterdiurnal frequency bands (D2 and D4) 
are calculated. This method is particularly appropriate to analyse tides in upper estuarine reaches and, unlike other non-stationary tidal analysis methods, it does not require long time series of water level data (Jalón-Rojas et al. 2018). Steps of the complex demodulation method application are briefly discussed in the Appendix. Further, detailed information about the method can be also found in Bloomfield (2004) and Jalón-Rojas et al. (2018) .

\section{- Calculation of the total friction}

To investigate the sources of subtidal water level variation, the subtidal friction term is decomposed into contributions from river flow, tidal motion, and interaction between tidal motions and river flow, following Bushman et al. (2009). This method was previously used in several studies (e.g. Guo et al. 2015) to explain the influence of river flow on tidal water level variations. The detected subtidal friction variations are explained based on the total current decomposition by $U=U_{0}+U_{1} \cos \left(\omega_{1} t+\emptyset_{1}\right)+U_{2} \cos \left(\omega_{2} t+\emptyset_{2}\right)+U_{4} \cos \left(\omega_{4} t+\emptyset_{4}\right)$ and an approximation of the quadratic friction by $U|U| \approx a U+b U^{3}$, where $\mathrm{U}_{0}$ is the nondimensional residual velocity amplitude, $\mathrm{U}_{1}, \mathrm{U}_{2}$ and $\mathrm{U}_{4}$ are diurnal, semidiurnal and quarterdiurnal nondimensional velocity amplitudes respectively, $\omega$ is the angular frequency of the respective tidal component and $\emptyset_{1}, \emptyset_{2}, \emptyset_{4}$ are diurnal, semidiurnal and quarterdiurnal phase lags, respectively and $\mathrm{a}$ and $\mathrm{b}$ are constants. Velocity components are normalised by dividing by the maximum current velocity. Integration of the friction term over a diurnal tidal cycle leads to three subtidal friction terms (Buschman et al., 2009), as follows:

$$
\begin{gathered}
F_{r}=a U_{0}+b U_{0}^{3} \\
F_{r t}=1.5 b U_{0}\left(U_{1}^{2}+U_{2}^{2}+U_{4}^{2}\right) \\
F_{t}=0.75 b\left[U_{1}^{2} U_{2} \cos \left(2 \emptyset_{1}-\emptyset_{2}\right)+U_{2}^{2} U_{4} \cos \left(2 \emptyset_{2}-\emptyset_{4}\right)\right] \\
F_{a}=F_{r}+F_{t}+F_{r t}
\end{gathered}
$$

Equations 1, 2 and 3 indicate that the subtidal variations of tidal currents induce variations in the subtidal friction, which result in subtidal water level variations. The values for $U_{i}$ and $\emptyset_{i}$ are derived from the complex demodulation analysis of the model simulated time series tidal currents. The constants $\mathrm{a}$ and $\mathrm{b}$ are set to 0.3395 and 0.6791 , respectively following Godin (1999).

\section{Result and Discussion}

\subsection{Model validation}

The model setup is validated using an average flood year condition (2000), which has a large amount of water level data available. The modeled water levels and tidal constituents are first compared with the available observations. Figure 2a-c shows this comparison for water level at stations E1, E2 and E3. Table 1 shows the statistical agreement between the modeled and the observed water level for stations recording continuous water levels (E1-E3).

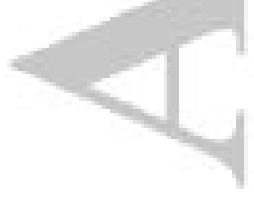


In addition, the stationary harmonic analysis is applied to observed and modelled water level at these stations and the tidal constituents are compared (Table 2).

There is a reasonably good agreement between modeled and observed water levels with correlation coefficient values $\left(\mathrm{R}^{2}\right)$ above 0.91 at all three stations (Table 1). The highest Mean Squared Error (MSE) occurs at E2 $\left(0.40 \mathrm{~m}^{2}\right)$, with lower MSE values calculated at E1 $\left(0.22 \mathrm{~m}^{2}\right)$ and E2 $\left(0.27 \mathrm{~m}^{2}\right)$. The mean absolute percentage errors (MAPE) are below $25 \%$ at all stations except at E2 (42.75\%). The error values at E2 are likely higher because the model water level is slightly underestimated during the monsoon period, which might be attributed to less accurate bathymetry in that location. E2 is located in shallow water between two islands where the river morphology changes rapidly (Figure 1a). The comparison of tidal constituents also shows that the model has successfully simulated the tidal forcing (Table 2). This comparison is particularly good at E1 and E3 with very good agreement between model and observed amplitudes of different tidal constituents. Absolute errors (define as the absolute difference between the observed and model data) for the M2 tide are 0.05, 0.08 and $0.02 \mathrm{~m}$ at E1, E2 and E3, respectively. The absolute errors for the phase of different tidal constituents also exhibit good agreement. For example, the absolute errors for the M2 tide phases are 14.79, 24.17 and 3.66 degrees at E1, E2 and E3, respectively. The amplitude and phase of the MSF tide has lower agreement compared to other tidal components at all the three stations (Table 2). Compound tides like the MSF tide are generated from the interaction between principal tides and residual flow velocity. The lower agreement of the MSF tide may be related to the discrepancy between the real and modeled bathymetry, and model residual flow velocity. However, other principal tides demonstrate good agreement with the observed data.

Only daily maximum and minimum water level data are available along Meghna River from R1 to R10, so it is not possible to compare observed and modeled tidal constituents at these stations. However, the modeled and observed tidal ranges are compared from R1 to R10 along the GBMD to validate the model setup (Table 3, Figure 2d for R3). Most of the stations show overall good agreement with the observed tidal ranges, which provides confidence to apply the model for further analysis (Mean $\mathrm{R}^{2}>0.50$ for R3, R6, E1, $\mathrm{E} 2$, and E3). However, the mean $\mathrm{R}^{2}$ is lower at $\mathrm{R} 4, \mathrm{R} 5$, and $\mathrm{R} 8(0.18,0.21$ and 0.13 , respectively). Previous numerical hydrodynamic studies in the GBMD (e.g. Bricheno et al., 2016, Tazkia et al. 2017) also found a lower agreement in the tidal range at these stations. For example, Bricheno et al. (2016) underpredicted tidal range by $1.63 \mathrm{~m}$ at R8 (observed and model tidal ranges are 2.63 and $1 \mathrm{~m}$, respectively). These previous studies neglected the varying embankment height on the coast, several channel networks, and the complex bathymetry, and mentioned the importance of using accurate bathymetry for better model results. In the current study, complex bathymetry (e.g., channel 1, 2 and 3 in Figure 1b) has been incorporated. The spatial embankment heights are also considered during bathymetry preparation in the coast based on the BWDB embankment heights. These set-up efforts, together with a new calibration of the roughness coefficient (Section 3.2) have improved the prediction of tidal range compared with previous studies (e.g., tidal range of $1.42 \mathrm{~m}$ at R8). However, due to a lack of field measurements, it was not possible to include all these channels and shallow lands located in the rivers (e.g., locations 4 and 5 in Figure 1b). The presence of such shallow islands may result in a lower agreement with the observed tidal range at some stations. In summary, the lower agreement with the observed tidal range is probably due to the morphological characteristics of the GBMD, which are very dynamic and result in a rapid change of bathymetry in the mouth of the estuary and shallow islands located 
in the middle of the channels. However, the model is still capable of reproducing reasonable hydrodynamics in most of stations along the delta.
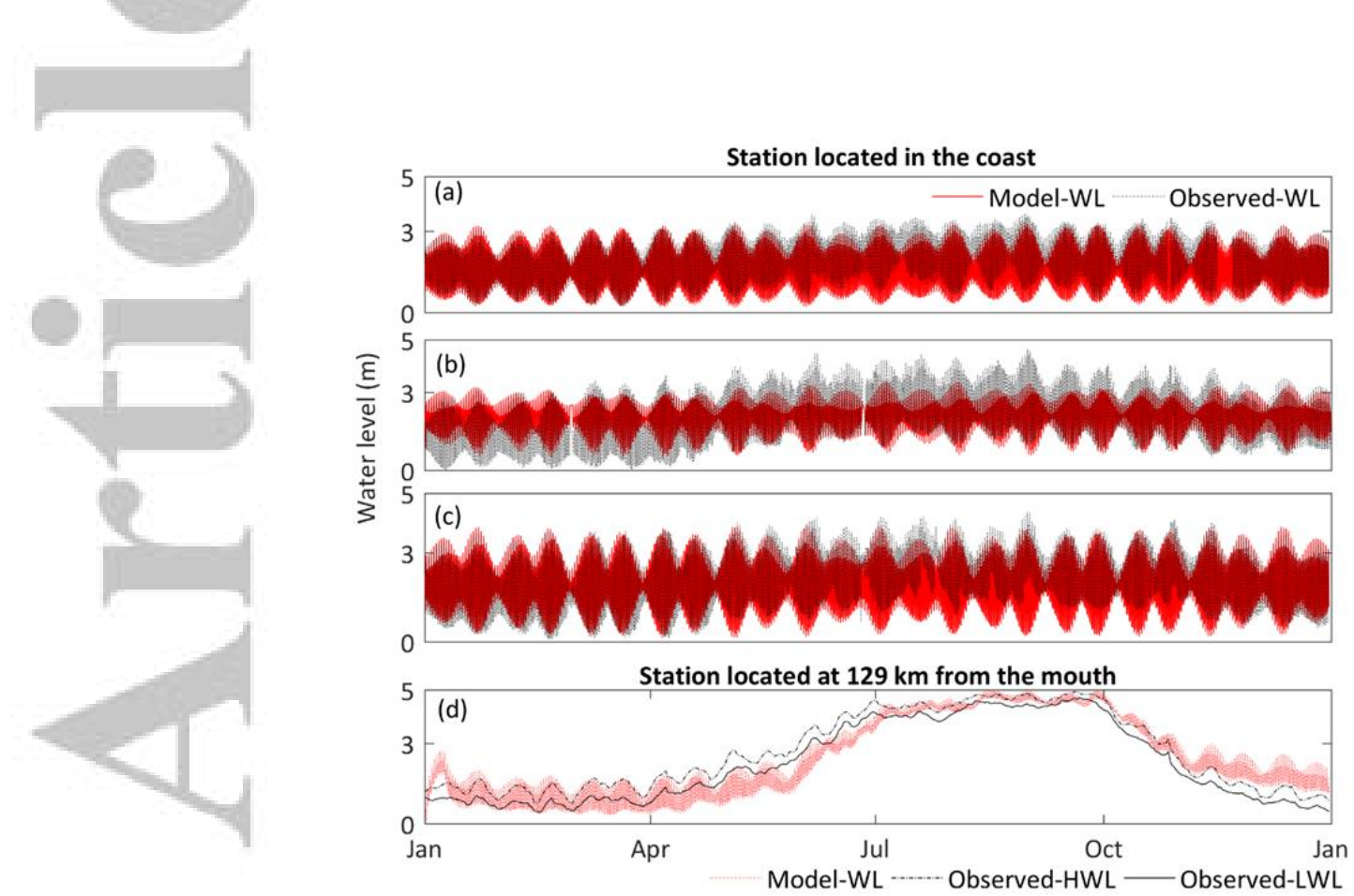

Figure 2. A comparison of simulated water levels with observations for the average flood conditions (2000) at: (a) E1; (b) E2; (c) E3; and (d) R3. HWL and LWL denote daily highwater and low-water levels, respectively.

Table 1. Statistical analysis of model water level compared with observations for 2000.

\section{Statistical analysis}

MSE: Mean Squared Error $\left(\mathrm{m}^{2}\right)$

PSNR: Peak signal-to-noise ratio

$\mathrm{R}^{2}$ :

RMSE: Root-mean-square error (m)

NRMSE: Normalized root-mean-square error

MAPE: Mean Absolute Percentage Error (\%)

\begin{tabular}{rrr}
\multicolumn{1}{c}{ E1 } & \multicolumn{1}{c}{ E2 } & \multicolumn{1}{c}{ E3 } \\
\hline 0.22 & 0.40 & 0.27 \\
54.80 & 52.10 & 53.89 \\
0.95 & 0.92 & 0.94 \\
0.46 & 0.63 & 0.52 \\
0.12 & 0.13 & 0.12 \\
21.31 & 42.75 & 24.80
\end{tabular}


Table 2. Comparison of model tidal amplitude and phase with observations: 2000

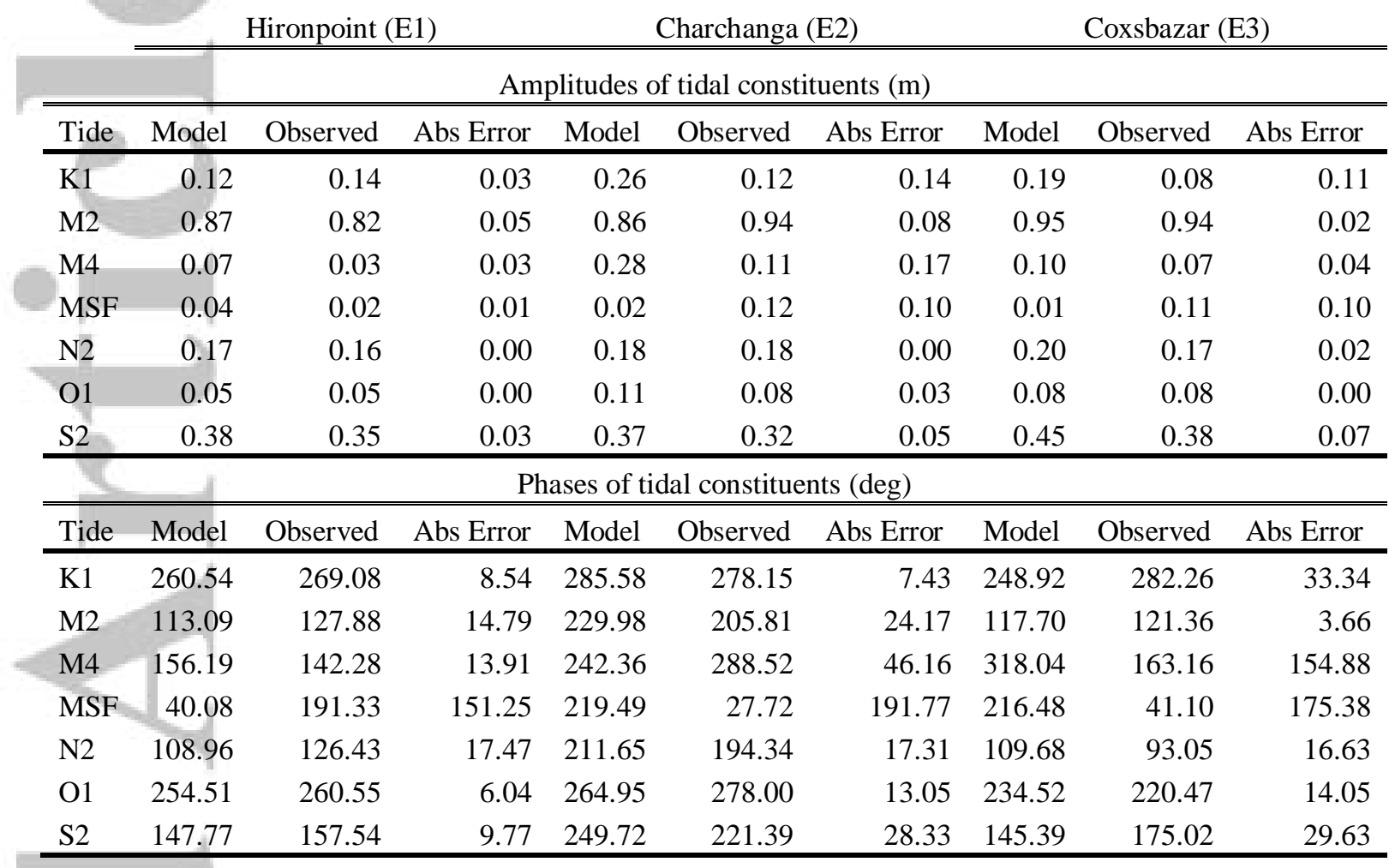

Table 3. Mean $\mathrm{R}^{2}$ values of model tidal range for 2000

\begin{tabular}{|c|c|c|c|c|c|}
\hline Station name & Notation/ & $\overline{M e a n ~} \mathbf{R}^{2}$ & Station name & Notation/ & Mean \\
\hline 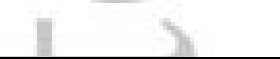 & Dist. (km) & value & & Dist. (km) & $\mathbf{R}^{2}$ value \\
\hline Baruria Transit & R1 (205) & No tide data & Tajumuddin & R8 (32) & 0.13 \\
\hline Mawa & R2 (152) & No tide data & $\begin{array}{l}\text { Meghna } \\
\text { mouth }\end{array}$ & R9 (0) & No data \\
\hline Sureswar & R3 (129) & 0.56 & Hatiya & $\mathrm{R} 10$ & 0.49 \\
\hline Chandpur & R4 (115) & 0.18 & Hironpoint & E1 & 0.90 \\
\hline Nilkamal & R5 (102) & 0.21 & Charchanga & E2 & 0.70 \\
\hline Charramdaspur & R6 (69) & 0.50 & Cox's bazar & E3 & 0.69 \\
\hline Daulatkhan & R7 (49) & No data & & & \\
\hline
\end{tabular}

*All the distances are from $\mathrm{R} 9$.

\subsection{Temporal and spatial variation of tides}

The model results show that water level varies seasonally with river discharge along the GBMD. In particular, the water level in the upper estuary is significantly higher during the high river discharge period. It can rise from $2 \mathrm{~m}$ at low discharge to $10 \mathrm{~m}$ at high discharge in R1 (see Fig. S1 in the supporting information). The water level variability with the springneap tidal cycles is higher at the stations closer to the mouth, whereas the landward stations show minimal variations during both the high and low river discharge. To evaluate the 
influence of river discharge on tides, water level time series are decomposed in frequency components. First, stationary harmonic analysis is applied to identify the main harmonic components along the tidal river. Semidiurnal (M2, N2), diurnal (O1, K1), quarterdiurnal (M4) and fortnightly (MSF) components are the main tidal harmonics in the GBMD and their variabilities along the tidal river is presented in Appendix B. The diurnal to semidiurnal amplitude ratio $(\mathrm{K} 1+\mathrm{O} 1) /(\mathrm{M} 2+\mathrm{S} 2)$ is 0.57 at the estuary mouth $(\mathrm{R} 9)$, which denotes a mixed tidal regime. However, this stationary harmonic analysis does not reproduce time-varying properties such as characteristics of tidal-river dynamics, so these results are not discussed further. Instead, the estimated tidal frequencies are used to apply a non-stationary method based on complex demodulation.

The Complex Demodulation method provides a time series of semidiurnal (D2), quarterdiurnal (D4), diurnal (D1) and fortnightly (MSF) components at each station along the GBMD (see methodological details in Section 3.3). Figure 3 shows the temporal variation of the total tidal range, the amplitudes of the D1, D2 and D4 components, and the river flow for the study year 2000. Trends can be divided into three groups depending on the location of the station along the longitudinal axis of the GBMD:

- In the lower GBMD (R6-R8, first $70 \mathrm{~km}$ from the estuary mouth), the tidal range varies between $2.98 \mathrm{~m}$ (at R8) to $3.32 \mathrm{~m}$ (at R7). There is an increase in the maximum tidal range by $0.24 \mathrm{~m}$ at R7. Amplitudes of D2 shows a steadily decreasing trend from R8 to R6. The maximum amplitude of both the D2 and D4 tides occur at R7: $1.13 \mathrm{~m}$ and $0.16 \mathrm{~m}$, respectively, during the spring tide. The amplitude of D1 shows slight decreasing trend from R8 to R6. In general, the tidal ranges and amplitudes at R6-R8 (within $50 \mathrm{~km}$ of the estuary mouth) exhibit large spring-neap tide variation, but no significant seasonal variation, which suggests that river discharge has marginal influence in the lower estuary.

- In the upper-middle GBMD (R2-R5, approximately 102-152 km upstream from the estuary mouth), the variability in tidal range and amplitude over the spring-neap cycles is lower, but there is a damping of all tidal components during the monsoon season. During the monsoon (June to October), when the river discharges are over $50,000 \mathrm{~m}^{3} \mathrm{~s}^{-1}$, tidal range is significantly reduced (by up to $0.5 \mathrm{~m}$ ) at R2 to R5 (100 $\mathrm{km}$ upstream) and then increased again during the post-monsoon period (October to November). In the middle estuary (R5), the lowest values of the tidal range $(0.57 \mathrm{~m})$, D1 $(0.01 \mathrm{~m}), \mathrm{D} 2(0.19 \mathrm{~m})$ and D4 $(0.009 \mathrm{~m})$ are found in early October during the maximum combined river discharge $\left(>63,000 \mathrm{~m}^{3} \mathrm{~s}^{-1}\right)$. At R5, D4 is higher than for downstream stations during the neap tide during the dry season. (e.g., R5, the thick dashed line in Figure 3c). This phenomenon is due to the balancing act of D4 tide generation and dissipation and will be further examined in the next section. During the monsoon period, the D4 tide at R5 is reduced by $0.02 \mathrm{~m}$ but is still higher than for downstream stations such as R8 during the neap tide. In the upper estuary (R2), both the D2 and D4 tides are diminished during the monsoon. The maximum tidal range at $\mathrm{R} 2$ ranges from $0.44 \mathrm{~m}$ to $0.87 \mathrm{~m}$ during neap and spring tides, respectively, during the dry season when the river discharge is below $10,000 \mathrm{~m}^{3} \mathrm{~s}^{-1}$.

- R1 (205 km from the mouth) is located near the limit of tidal propagation. Maximum and minimum tidal ranges are $0.38 \mathrm{~m}$ (in the dry season) and $0 \mathrm{~m}$ (in the monsoon season) for the average flooding year. The amplitudes of the D2 and D4 tides vary between 0 and $0.05 \mathrm{~m}$ and between 0 and $0.01 \mathrm{~m}$, respectively. Similarly, D1 tides 
varies between 0 to $0.03 \mathrm{~m}$ during the monsoon to dry season. The seasonal variability of tidal amplitudes is therefore low.

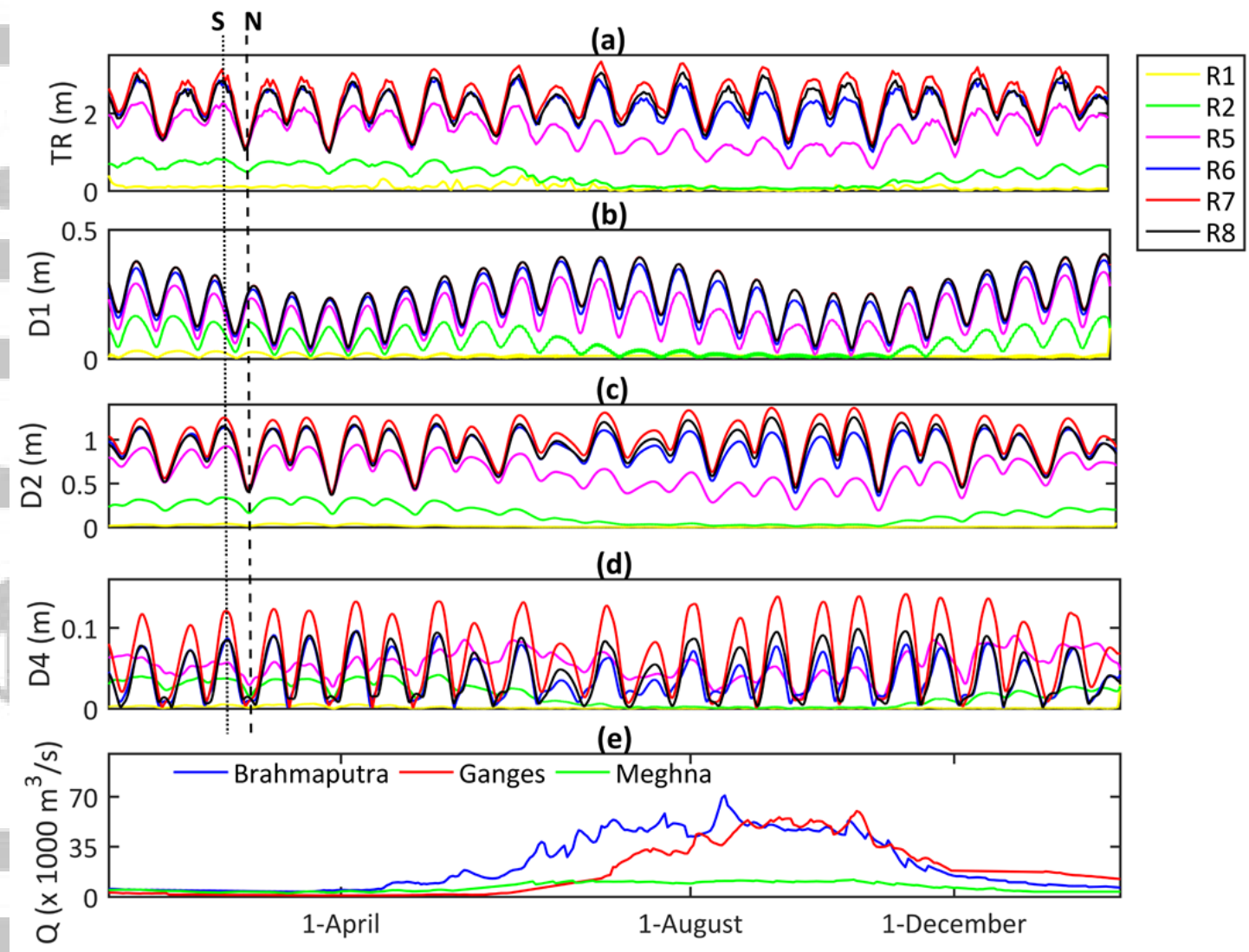

Figure 3. Tidal and river discharge conditions for the average flood conditions (2000): (a)

The model tidal range; (b) D1 amplitude; (c) D2 amplitude; (d) D4 amplitude; and (e) observed river discharge. Dotted and thick dashed lines denote typical spring and neap tide, respectively.

From Figure 3, it is evident that the stations beyond R5 exhibit substantial variations of tides with the river discharge. During the high river discharge period (July-October), both D2 and D4 tides are reduced in both spring and neap tides. For further understanding of the influence of river discharge on the D1, D2, D4 and MSF tides, four stations are plotted as a function of the combined Ganges-Brahmaputra-Meghna river discharge and the tidal range at the estuary mouth in Figure 4.

Results show that the amplitude of the D1 tide is approximately $0.60 \mathrm{~m}$ less than that of the amplitude of the D2 tide at R8, but 0.30 m higher than that of the amplitude of D4. The $\mathrm{D} 1$ tide varies with the spring-neap tides, from $0.04 \mathrm{~m}$ to $0.39 \mathrm{~m}$ at $\mathrm{R} 8$ and from $0.01 \mathrm{~m}$ to $0.16 \mathrm{~m}$ at $\mathrm{R} 2$. The $\mathrm{D} 1$ tide does not appear to vary with river discharge along the GBMD, but D1 tide variations in the spring-neap tide are slightly influenced by extremely high river discharges (Figure 4a-b). At R1, the D1 tide is zero indicating that it is damped by the weakening of the incoming tidal harmonics (Figure 4d).

The D2 tide is dominant at R5 and R8 compared to other tides. At R8, the amplitude of the D2 tide is higher during the spring tide compared to the neap tide period ( $1 \mathrm{~m}$ and 0.4 
$\mathrm{m}$, respectively, Figure 4a). These differences decrease for the upper stations as the impact of the river flow is more important. While the increase of river discharge does not influence the D2 tide variations at $\mathrm{R} 8$, it has a high impact on the other three stations. For a mean tidal range at the mouth, D2 decreases from $0.94 \mathrm{~m}$ to $0.19 \mathrm{~m}$ at R5 (Figure $4 \mathrm{~b}$ ), and from $0.34 \mathrm{~m}$ to $0.01 \mathrm{~m}$ at R2 (Figure 4c) for discharges of 5,000 and 100,000 $\mathrm{m}^{3} \mathrm{~s}^{-1}$, respectively. The damping of tides was explained by Godin (1999). This study shows that the tidal components contribute to their self-damping along with the mutual damping at a location where tides and river discharge show a strong influence on the water level. The self-damping arises from the velocity component that produces from the tidal harmonic, and the mutual damping is generated from the velocity components from the river discharge and other tidal harmonics. At R5, both the river discharge and spring-neap tide modulate the D2 tide and it is therefore influenced by both self-damping and mutual damping. Beyond R5, the spring-neap tides show lower water level variation compared to the river discharge. At R2, D2 is less than 0.5 $\mathrm{m}$ even with low river discharge $\left(5,000 \mathrm{~m}^{3} \mathrm{~s}^{-1}\right)$ and is wholly damped for discharges higher than $60,000 \mathrm{~m}^{3} \mathrm{~s}^{-1}$ (Figure 4c). D2 is completely damped at R1 for all volumes of river discharge (Figure 4d).

The D4 tide varies from $0.02 \mathrm{~m}$ to $0.16 \mathrm{~m}$ with the spring-neap tides at the estuary mouth (R8, Figure 4a). The increase of the river discharge significantly influences the D4 tide upstream starting from R5, while there is a lower variability with the spring-neap cycle. At $\mathrm{R} 5$, the increase of the river discharge up to approximately $30,000 \mathrm{~m}^{3} \mathrm{~s}^{-1}$ increases the D4 tide amplitude to a maximum $0.08 \mathrm{~m}$ (Figure $4 \mathrm{~b}$ ). Further increase of river discharge $\left(>30,000 \mathrm{~m}^{3} \mathrm{~s}^{-1}\right)$ reduces the $\mathrm{D} 4$ tide. A maximum analogue value for the $\mathrm{D} 4$ tide is also found at $\mathrm{R} 2$ for a river discharge of $10,000 \mathrm{~m}^{3} \mathrm{~s}^{-1}$ (Figure $4 \mathrm{c}$ ). This demonstrates the balancing act of generation and dissipation of the D4 tide that occurs with river discharge in a tidal estuary. According to Godin and Martinez (1994), the D4 tide is generated by friction, but also depends on the amplitude of the D2 tide. Higher levels of river discharge results in energy transfer from the D2 to D4 tide and enhances the friction. Up to river discharge amounts of $30,000 \mathrm{~m}^{3} \mathrm{~s}^{-1}$, the river-tide interaction may play an active role in the generation of the D4 tide at R5. Further increase of the river discharge makes the river discharge dominant over tides. Therefore, the increase in river discharge beyond an optimum volume dissipates the D4 tide rather than enhancing the generation of the D4 tide. The river-tide interaction mechanism in the generation and dissipation of the $\mathrm{D} 4$ tide will be discussed further in the next section.

The MSF tide dominates over the D2 tide at R2 (Figure 4c). All the tides are nearly zero $(<0.10 \mathrm{~m})$ at $\mathrm{R} 2$ when the total river discharge is above $40,000 \mathrm{~m}^{3} \mathrm{~s}^{-1}$ except the MSF tide. The results show that for increasing river discharge, the MSF tide increases with distance from the estuary mouth. According to Godin (1999), as the MSF tide is generated from the friction between double tidal harmonics and a net outflow of river discharge (which is the residual velocity), MSF cannot exist without the presence of the residual velocity component. The increase of river discharge increases the residual velocity component in the up-river direction. Moreover, MSF tide is not affected by self-damping due to the lower velocity produced from the MSF tide. Therefore, the MSF tide increases with increasing river discharge. 


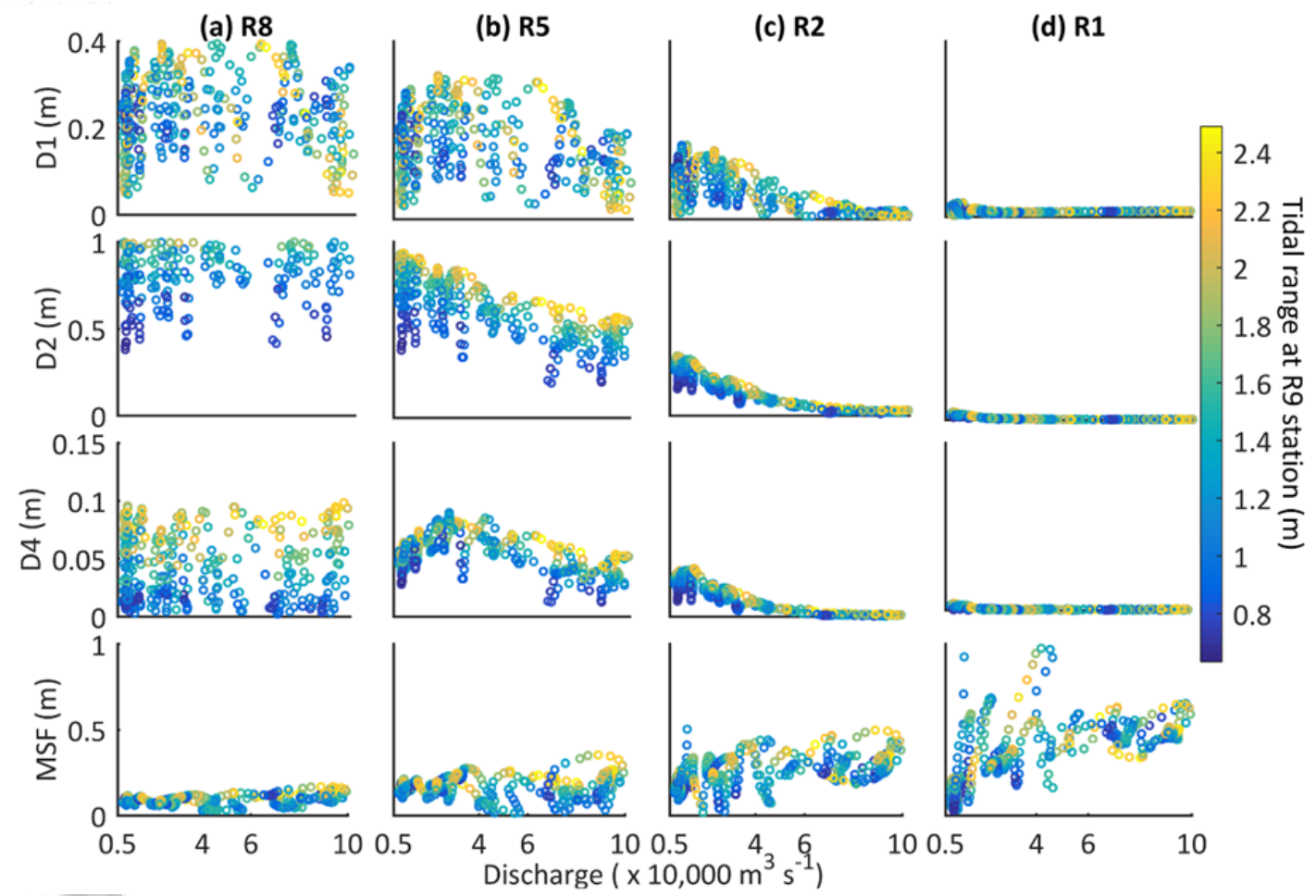

Figure 4. Tidal constituents (D1, D2, D4 and MSF) as a function of river discharge and tidal range at the estuary mouth (color bar) at: (a) R8; (b) R5; (c) R2; and (d) R1. Note that the Yaxis ranges have different scales.
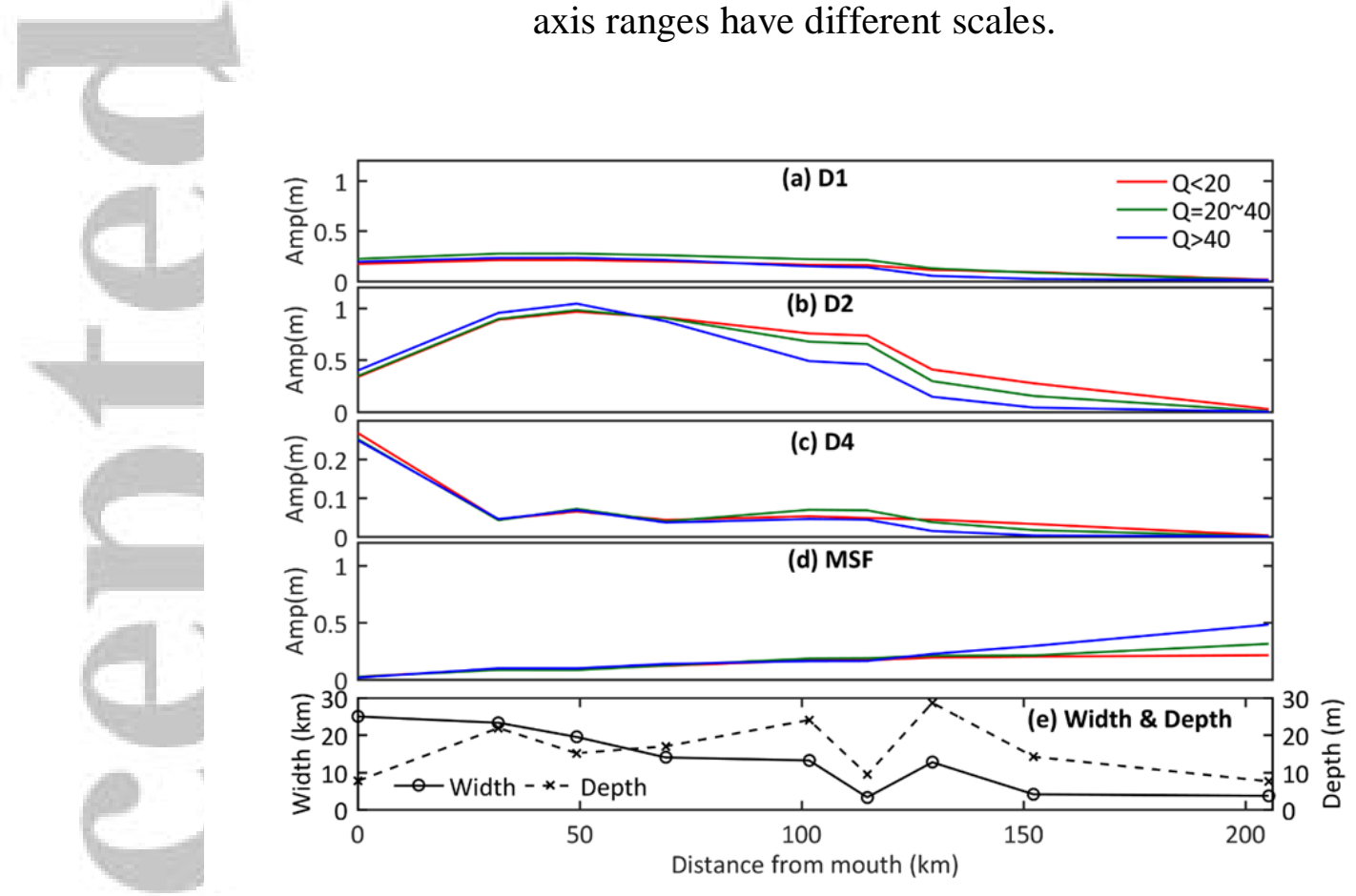

Figure 5. Spatial variations of tidal amplitudes: (a) D1; (b) D2; (c) D4; (d) MSF during different river discharge periods; and (e) Width and depth of the river along the GBMD. Q is the river discharge $\left(\times 1000 \mathrm{~m}^{3} \mathrm{~s}^{-1}\right.$. Amplitudes are averaged over the same river discharge period.

The spatial variations of averaged tidal amplitudes for different river discharge periods are illustrated in Figure 5. All the tidal components are completely diminished except the 
MSF tide by $205 \mathrm{~km}$ upstream of the estuary mouth regardless of the level of river discharge. The D1 tide shows little spatial variability with the river discharge periods along the GBMD (Figure 5a). The D4 tide exhibits maximum amplitude in the lower GBMD for all the river discharges, middle of the GBMD during average river discharge (green), and further upstream during low river discharge periods.

D2 tide exhibits more spatial variability, because of channel geometry (e.g., Bricheno et al., 2016). The Meghna estuary mouth is approximately $25 \mathrm{~km}$ wide decreasing to $18 \mathrm{~km}$ in the middle of the estuary ( $50 \mathrm{~km}$ upstream, Figure $5 \mathrm{~d}$ ). The depth of the Meghna river varies rapidly from approximately $3 \mathrm{~m}$ to $30 \mathrm{~m}$ between the estuary mouth and $\mathrm{R} 8$. The complex geomorphology including shallow shores and islands (e.g., Figure 1b) in the estuary along with the narrowing channel upstream results in amplification of the amplitude of the D2 tide approximately $50 \mathrm{~km}$ upstream of the estuary mouth. A slight rise $(<0.1 \mathrm{~m})$ in the D2 tide occurs during the high river discharge period compared to the low river discharge period at the locations close to the estuary mouth (e.g. at $50 \mathrm{~km}$, Figure 5b). Although river discharge shows minimal influence on tides at the mouth, it increases water depth at the estuary mouth. Therefore, the incoming tidal energy flux increases at the seaward stations and results in a slight rise of the D2 tidal amplitudes (e.g., Figure 7c). Further upstream, the amplitude of the D2 tide decreases regardless of the volume of river discharge. The decrease in D2 amplitude occurs most rapidly about $120 \mathrm{~km}$ upstream of the estuary mouth and during high river discharge, the D2 tide is completely damped by about $150 \mathrm{~km}$ upstream of the estuary mouth demonstrating the strong D2 tidal dissipation due to river discharge along the GBMD.

The MSF tide demonstrates little variation with river discharge up to $130 \mathrm{~km}$ from the estuary mouth. In the upper part of the GBMD, the MSF tide amplitudes are overall higher than the D2 tide and exhibits higher amplitude for higher river discharge. The damping of tidal harmonics is proportionally dependent on tidal frequency and the current produced by river discharge (LeBlond, 1978, Godin, 1999). The MSF tide period (355.2 hours), which is significantly higher than the D1 (24.8 hours), D2 (12.4 hours) and D4 (6.2 hours) tides, is damped less due to its low frequency. A similar increasing trend in the MSF tide is also found in the upper part of the Yangtze and Amazon estuary by Guo et al. (2015) and Gallo and Vinzon (2005), respectively. In Yangtze estuary, the MSF tide increased from $0.02 \mathrm{~m}$ to $0.2 \mathrm{~m}$ at $220 \mathrm{~km}$ from the estuary mouth. The MSF tide amplified to $0.18 \mathrm{~m}$ at 600 $\mathrm{km}$ in Amazon estuary. Gallo and Vinzon (2005) also show that the influence of river discharge resulted in higher MSF tide in the upper estuary and explained as the upstream propagation of long waves.

\subsection{River-tide interaction in the upper GBMD}

To further evaluate the influence of river discharge on tides, the effect of the residual slope generated from nonlinear friction on the propagation and damping of tides is analyzed, which can be significant in the presence of river discharge (Cai et al., 2014). River discharge affects tidal damping, mainly via a frictional term, and attenuates tidal motion by increasing the quadratic velocity in the numerator, while reducing the effective friction by increasing water depth in the denominator of the momentum equation (Cai et al., 2019). Based on the model tidal amplitudes $(\eta)$ and residual water level $(Z)$, tidal damping rate $(\delta)$ and residual water level slope (S) are estimated over a reach of length by the following equations:

$$
\delta=\frac{\eta_{2}-\eta_{1}}{\Delta x}
$$




$$
S=\frac{\mathrm{Z}_{2}-\mathrm{Z}_{1}}{\Delta x}
$$

where, $\eta_{1}$ and $Z_{1}$ are the tidal amplitude and residual water level on the seaward side, respectively, and $\eta_{2}$ and $Z_{2}$ are the corresponding values at a distance of $\Delta x$ upstream, respectively. Figure 6 shows the tidal damping rate and residual water level slope as a function of river discharge and the tidal range at the mouth for the year 2000. Positive tidal damping rate denotes the amplification of tidal amplitudes so this parameter is referred to as tidal amplification rate. As the D2 tide is dominant over other tides, the tidal damping/amplification rate is calculated based on the D2 tide. Figure 6a-b illustrates that river discharge has a marginal influence on tidal damping at the lower study area (e.g. R7-R8, R8-R9), whereas both the tidal damping rate and residual water slope increases with the river discharge beyond the middle of the channel (from R5). The tidal damping rate shows a decreasing trend in the upper study area with the increase of river discharge due to the high dissipation of tide at those stations. For example, the tidal damping rate is nearly zero at R1$\mathrm{R} 2$ during high river discharge because that tide is almost diminished at the seaward station R2. Residual water level slopes show different trends with river discharge beyond the middle of the channel (Fig. 6b). High river discharges result in nearly constant residual water level slopes at R1-R2 and R2-R3 from the combined effect of the channel storage capacity limit and the full dissipation of tides. For example, above 40,000 m3 s-1 of river discharge, the channel storage capacity at R1-R2 is over the maximum limit. Therefore, further increase of river discharge only causes increased inundation in the floodplain area rather than an increase of total friction (see Fig. 9a and b) and thus residual water level slope. However, the residual water level slope at R5-R6 shows a different trend compared with R1-R2 and R2-R3 due to the presence of stronger tides during high river discharge. High river discharges cannot fully diminish the tides at R5-R6 (Fig. 3c). This result corroborates the influence of river discharge on tide dissipation beyond the middle of the study area. Figure $6 \mathrm{c}$ shows a higher amplification of tidal amplitudes in the lower estuary (R7-R8 and R8-R9), particularly during spring tides. This amplification is a result of the shoaling effect due to channel convergence between R9 and R7. The damping rate at R5-R6 increases with the tidal range at the mouth due to a combined influence of river discharge and self-damping of the D2 tide. The higher damping is caused by the self-damping (produced from the tidal harmonic) and mutual damping (generated from the influence of river and other tidal harmonics) (Godin, 1999). Moreover, the residual water slope variations do not show any specific trend with the tidal ranges since they are driven by subtidal friction. At the mouth, the residual water slope is nearly constant due to the dominant influence of subtidal friction related to tide and river-tide interaction (Fig. 9c-d). The role of frictions on the tide modulation is discussed later in this section. 

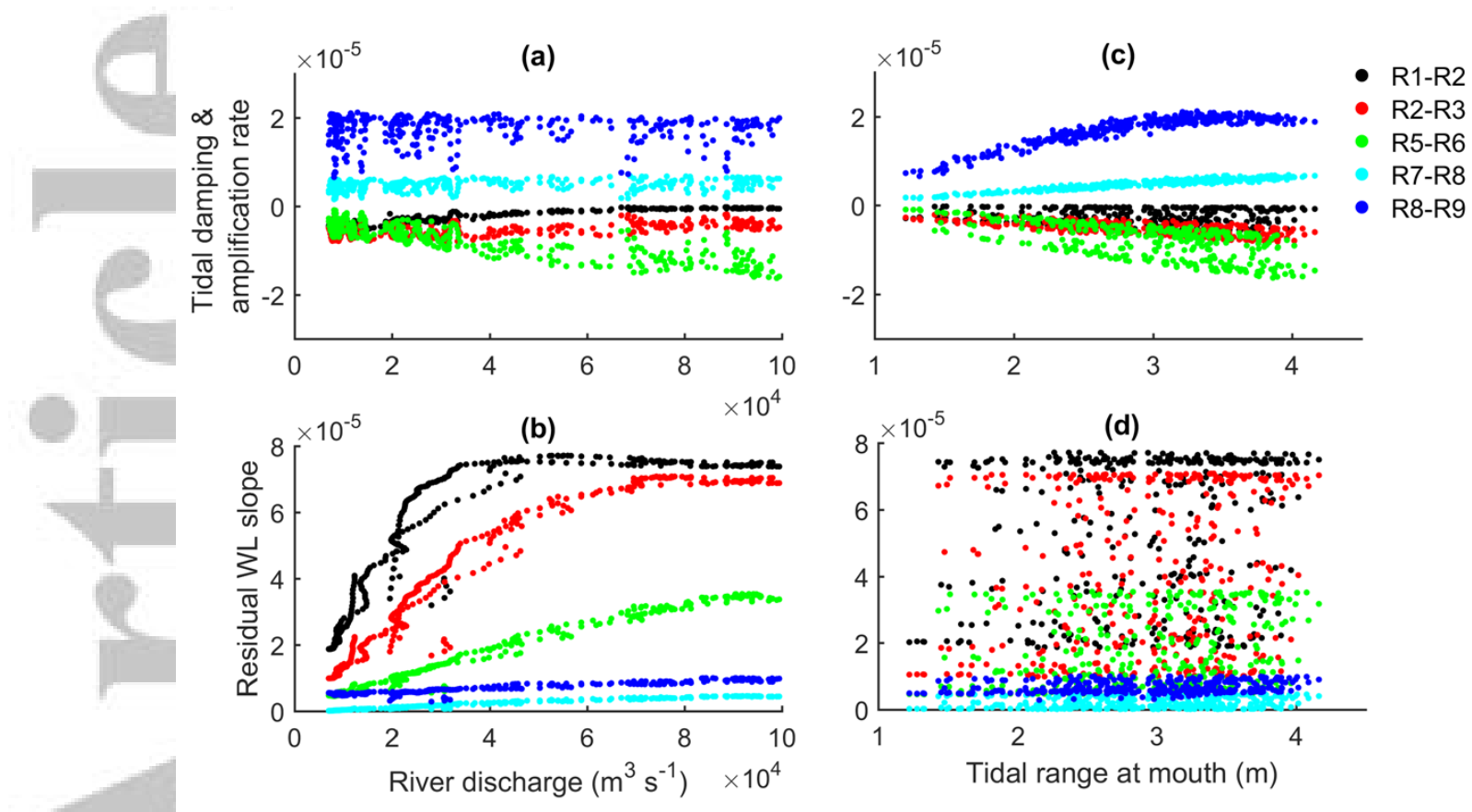

Figure 6. Tidal damping rate and residual water level slope variations with the river discharge $(a, b)$ and tidal range at mouth $(c, d)$ for the study year.

To further assess the influence of the river discharge on tides in the GBMD, nine idealized river discharge scenarios are examined. The simulations are run for 31 days and include the spring-neap tide of March 2000. The first and last four days of the simulation are ignored to avoid any error produced by applying the low-pass filter at the boundaries of time series in the complex demodulation method (see formulation in Appendix A). Hereafter, the river discharge scenarios are denoted as Q00 (no river discharge), Q05 $\left(5,000 \mathrm{~m}^{3} \mathrm{~s}^{-1}\right.$, multiplying the number by $1,000 \mathrm{~m}^{3} \mathrm{~s}^{-1}$ represents river discharge amount), Q10, Q20, Q40, Q60, Q80, Q100 and Q125 $\left(125,000 \mathrm{~m}^{3} \mathrm{~s}^{-1}\right)$. From the observed river discharge in the average flooding year (2000), the Ganges, Brahmaputra, and Meghna rivers are calculated to contribute $32 \%, 51 \%$, and $17 \%$ of the total river discharge, respectively. Therefore, the total river discharge is distributed among the three rivers following these percentages for each idealized scenario. The tidal forcings from the average year (March 2000) are used for the downstream boundary condition. The current study focuses on the influence of river discharge on tides, and both D1 and MSF tide shows less variability with river discharges compared to D2 tide (Figure 4 and Figure 5). Therefore, the analysis on the relationship between tides and river discharge focuses on the D2 and D4 tidal constituents.

Figure 7 illustrates spatial and temporal variations of D2 and D4 along the GBMD for the idealized scenarios. For better graphical representation and avoiding overlap, the Q05, Q80 and Q100 discharge scenarios are not presented in Figure 7. As expected from the earlier results, the amplitude of $\mathrm{D} 2$ reaches a minimum value for the highest river discharge scenario (Q125). The no river discharge scenario results in a maximum amplitude of D2 among all idealized scenarios (Q0 in Figure 7a). This suggests an inverse relationship between the amount of river discharge and the amplitude of the D2 tide at R2 (152 km from the estuary mouth).

This inverse relationship is also apparent for D4 with one interesting difference. The zero-river discharge scenario has a D4 component (maximum $0.02 \mathrm{~m}$ and minimum $0.01 \mathrm{~m}$ ) with lower amplitude than for Q10 (maximum $0.04 \mathrm{~m}$ and minimum 0.01) and Q20 
(maximum $0.04 \mathrm{~m}$ and minimum $0.01 \mathrm{~m}$ ) discharge scenarios (Figure $7 \mathrm{~b}$ ). This may result from the influence of the river-tide interaction in the friction term, which will be addressed later in this section. The distribution of maximum D2 and D4 amplitudes (Figure 7c-d) indicates that the maximum spatial variations of these amplitudes with river discharge occur between 100 to $150 \mathrm{~km}$ inland from the estuary mouth.

The tidal limit varies between 205 to $130 \mathrm{~km}$ from the estuary mouth for river discharges from Q00 to Q125, respectively. During the monsoon period in the average flood year $\left(>60,000 \mathrm{~m}^{3} \mathrm{~s}^{-1}\right)$, tides are diminished at $152 \mathrm{~km}$ from the estuary mouth. Regardless of the river discharge, tides become insignificant $(\mathrm{D} 2<0.15 \mathrm{~m}$, approximate $10 \%$ of the amplitudes at the estuary mouth) beyond $190 \mathrm{~km}$ from the estuary mouth compared to the estuary mouth. Though the D2 amplitude exhibits a similar rate of change with river discharge along the estuary, the rate of the change for the D4 amplitude shows a different variation with river discharge beyond $100 \mathrm{~km}$ from the estuary mouth (Figure $7 \mathrm{c}-\mathrm{d}$ ).
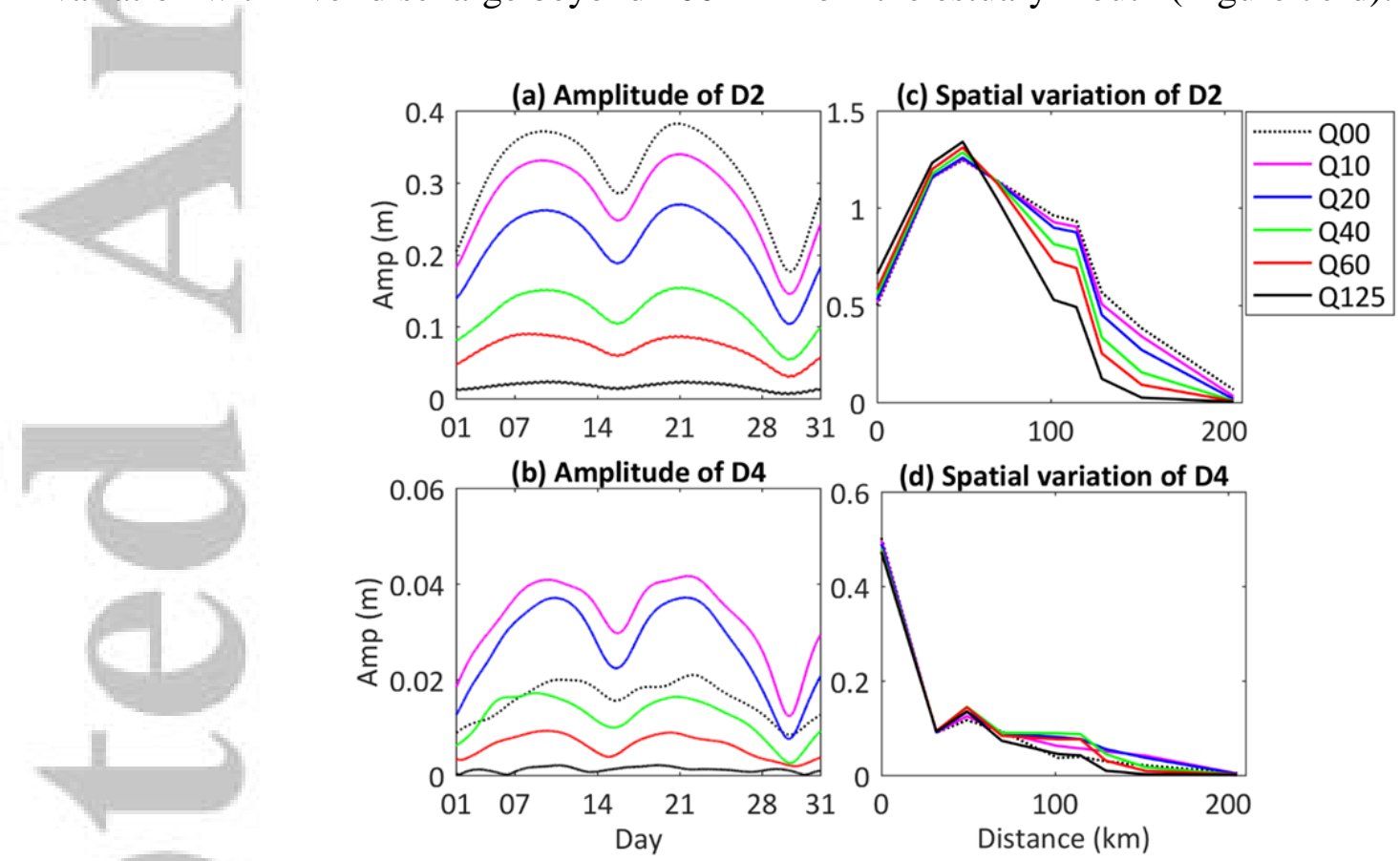

Figure 7. Simulated influence on the tide at $\mathrm{R} 2$ for a variety of idealized river discharges (Total discharge represented in the legend is in $\mathrm{x} 1000 \mathrm{~m}^{3} \mathrm{~s}^{-1}$, e.g., Q125 $=125,000 \mathrm{~m}^{3} \mathrm{~s}^{-1}$ ): (a) amplitude of the D2; and (b) D4 tide variation with river discharge; spatial variation of the maximum amplitude of: (c) D2; and (d) D4 tide with distance from the estuary mouth.

To identify the mechanism that controls tides in the upper estuary, 10 additional different idealistic scenarios consisting of combinations of river discharge and tidal forcings are simulated (see description in Table 4). The simulation period and tide forcing of the idealistic scenarios are kept the same as for the first set of idealized simulations. Figure 8 shows the D2 and D4 amplitudes variation at R2 from these simulations. In general, the M2forced simulations generate both D2 and D4 components, while the corresponding M4-forced simulations generate no D4 component at $\mathrm{R} 2$ regardless of the river discharge. This indicates that the D4 component is generated locally from the energy transfer of principal tides (D2 tide) by total friction and non-linear interactions of the tide, including river-tides interactions. 
Table 4. Idealistic scenarios with different boundary forcing

\begin{tabular}{lll}
\hline Run & $\begin{array}{l}\text { River } \\
\text { discharge } \\
\left(\mathbf{m}^{\mathbf{3} / \mathbf{s})}\right.\end{array}$ & Tide forcing \\
\hline Q10 M2 & 10,000 & Only M2 \\
Q10 M4 & 10,000 & Only M4 \\
Q10 Tide & 10,000 & All tidal constituents \\
Q10 No tide & 10,000 & No tidal effects \\
Q00 M2 & No discharge & Only M2 \\
Q00 M4 & No discharge & Only M4 \\
Q20 M2 & 20,000 & Only M2 \\
Q20 M4 & 20,000 & Only M4 \\
Q40 M2 & 40,000 & Only M2 \\
Q60 M2 & 60,000 & Only M2 \\
\hline
\end{tabular}

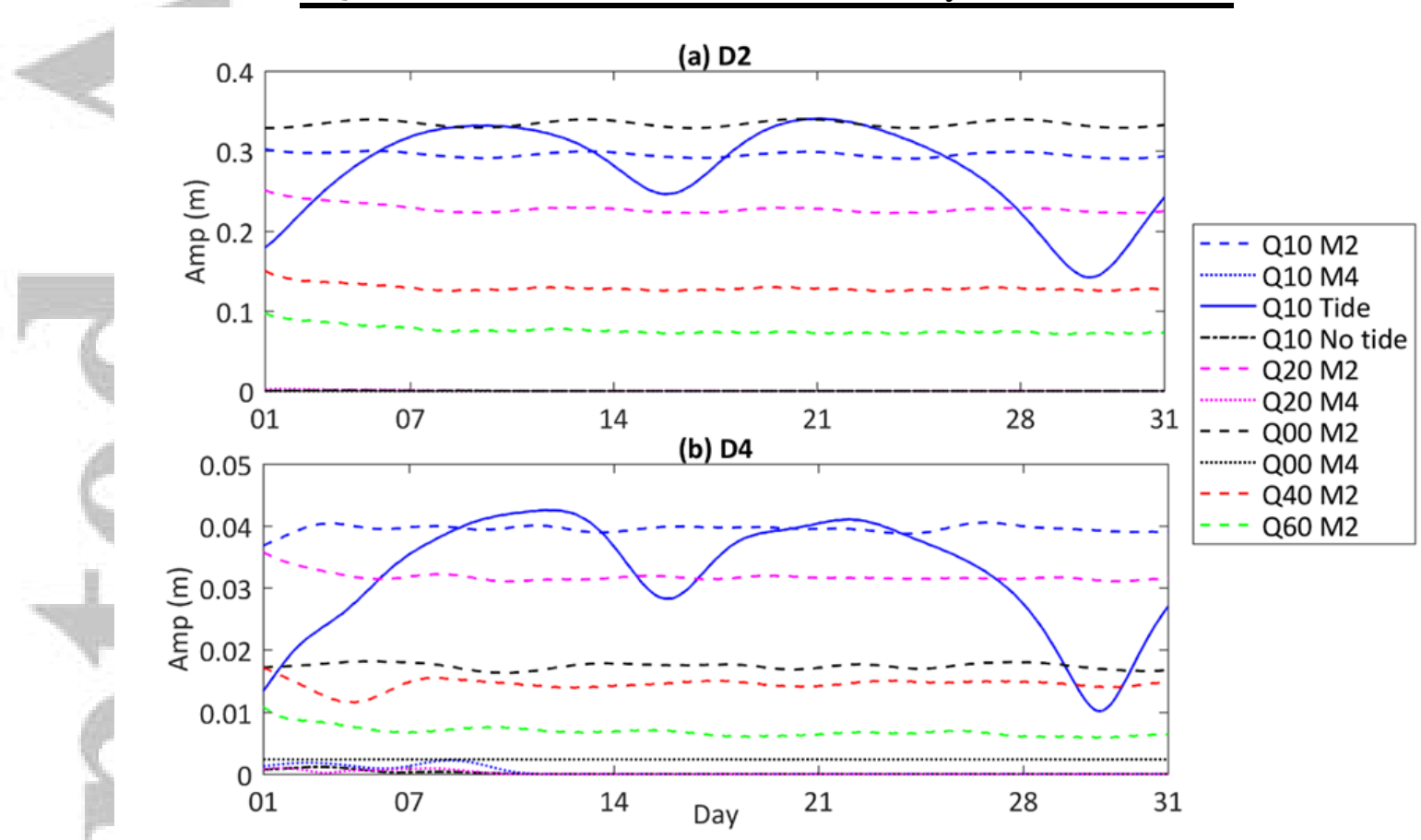

Figure 8. Amplitudes of: (a) D2; and (b) D4 tide variations at R2 for different boundary and tidal forcing.

The generation and dissipation of D4 tide are related to its principal companion D2 tide. According to Godin (1999), all tidal components are damped uniformly in the upper regions (where tide is nearing extinction) of a river by the flow velocity due to river discharge. At the same time, frictional nonlinearities also act as a generating mechanism for overtides (e.g., D4), until they reach a point upstream where they are damped more rapidly by friction than they are generated through nonlinear interaction (Matte et al. , 2014). As dissipation of principle tides causes the generation of overtides, the generation of D4 tide has one source: energy transfer from the principle tides to higher frequency tides due to total 
friction, i.e., dissipation of the D2 tide generates D4 tide. This balancing act between the dissipation and generation of D4 is highlighted in the GBMD.

For a quantitative understanding of the role of friction on tides modulation in the GBMD, the friction term is calculated and decomposed into contributions from river discharge, tide, and river-tide interaction by following Bushman et al. (2009), as shown in Equation 1-4. By applying the complex demodulation, $U_{i}$ and $\emptyset_{i}$ are estimated from the modeled river and tidal current components for the different idealized scenarios along the GBMD (Table 5). The result of frictional term decomposition along the GBMD (Figure 9) shows that the maximum total friction varies $0.2-0.3 \mathrm{~N} \mathrm{~m}^{-2}$ with increasing river discharge between $0-50 \mathrm{~km}$ from the estuary mouth. The maximum total friction exhibits significant variation with river discharge beyond $100 \mathrm{~km}$ from the mouth. The friction related to tide is higher beyond $100 \mathrm{~km}$ from the mouth for low river discharge scenarios compared to high river discharge scenarios. The friction related to river contributes a significant portion of the total friction along the GBMD.

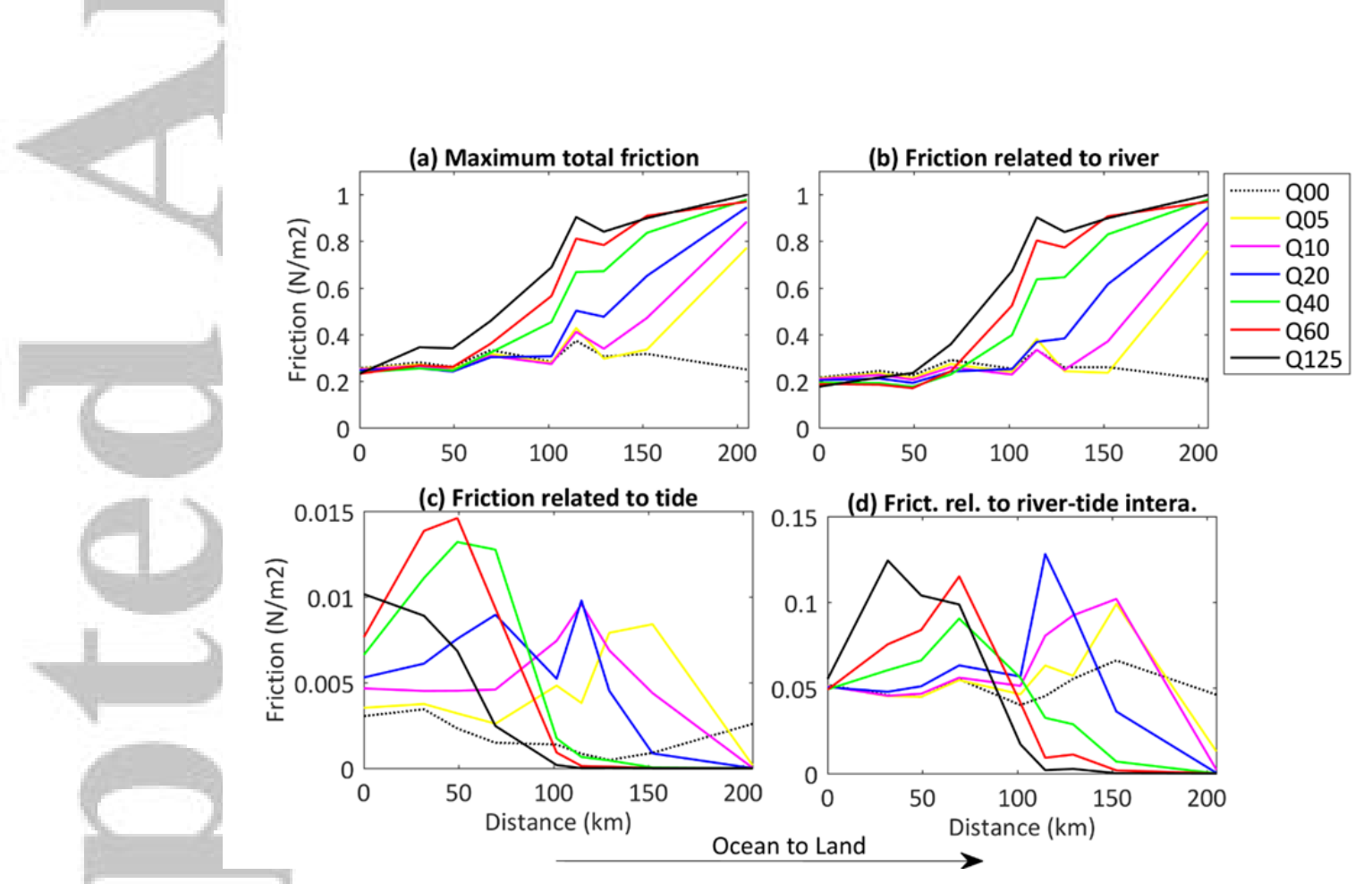

Figure 9. (a) Maximum total friction, (b) maximum friction related to river, (c) maximum friction related to tide and (d) maximum friction related to river-tide interaction according to Equation 1-4. Ui and $\emptyset \mathrm{i}$ are calculated from the model simulated river and tidal current components for different idealized scenarios along the GBMD. Note that y-axes are on different scales. 
As discussed from Figure 8, D4 tide is generated locally from energy transfer from the D2 tide through friction. Figure 9d shows the variations of friction related to river-tide interaction. Higher river discharges produce lower friction related to river-tide interaction beyond $100 \mathrm{~km}$ from the mouth. The residual velocity highly influenced by river discharge reduces the friction related to river-tide interaction beyond this point. The friction related to river-tide interaction varies between $0.05-0.12 \mathrm{~N} \mathrm{~m}^{-2}$ up to $100 \mathrm{~km}$ from the mouth. At 152 $\mathrm{km}(\mathrm{R} 2)$, the maximum friction related to river-tide interaction $\left(0.10 \mathrm{~N} \mathrm{~m}^{-2}\right)$ is found in the Q10 scenario among all the idealized scenarios, whereas the maximum total friction occurs in the Q60 scenario $\left(0.91 \mathrm{~N} \mathrm{~m}^{-2}\right)$. Figure $7 \mathrm{~d}$ demonstrates that the Q10 scenario generates a higher D4 tide than the Q60 scenario. Therefore, it appears that friction related to river-tide interaction plays a vital role in the generation of D4 though its magnitude is smaller compared to the total friction.

The variations of friction related to river-tide interaction depend on the residual velocity and tidal velocity components. According to Godin (1999), higher frequency tides are generated from the interaction between residual flow and principal tides. The study defined the frictional coefficient as $U_{0}\left(U_{2}^{2}\right)$ for D4 tide generation from the development of the quadratic friction term in Newton's equation of motion. Buschman et al. (2009) decomposed the frictional term further into each tidal harmonic constituent (Eq. 1-4). Table 5 shows different non-dimensional velocity components that are affecting the friction related to river-tide interaction at $\mathrm{R} 2$.

Table 5. Maximum amplitude of the D2, and D4 tide, nondimensional maximum residual velocity $\left(\mathrm{U}_{0}\right)$, maximum velocity of diurnal $\left(\mathrm{U}_{1}\right)$, semi-diurnal $\left(\mathrm{U}_{2}\right)$ and maximum velocity of quarterdiurnal $\left(\mathrm{U}_{4}\right)$ tides, frictional coefficient from Godin (1999) and velocity components in the river-tide friction for the river discharge scenarios (Q00-125) at R2.

\begin{tabular}{|l|l|l|l|l|l|l|l|l|}
\hline $\begin{array}{l}\text { River } \\
\text { discharge } \\
(\text { in } \\
10,000 \\
\left.\mathrm{~m}^{3} \mathrm{~s}^{-1}\right)\end{array}$ & $\begin{array}{l}\text { Max } \\
\mathrm{U}_{0} \\
\left(\mathrm{u}_{0} / \mathrm{u}_{\max }\right)\end{array}$ & $\begin{array}{l}\text { Max } \\
\mathrm{U}_{1} \\
\left(\mathrm{u}_{1} / \mathrm{u}_{\max }\right)\end{array}$ & $\begin{array}{l}\text { Max } \\
\mathrm{U}_{2} \\
\left(\mathrm{u}_{2} / \mathrm{u}_{\max }\right)\end{array}$ & $\begin{array}{l}\text { Max } \\
\mathrm{U}_{4} \\
\left(\mathrm{u}_{4} / \mathrm{u}_{\max }\right)\end{array}$ & $\begin{array}{l}\text { Max Friction } \\
\text { coefficient } \\
\text { for D4 from } \\
\text { Godin,1999- } \\
U_{0}\left(U_{2}^{2}\right)\end{array}$ & $\begin{array}{l}\text { Max } \\
\text { Velocity } \\
\text { term in Frt } \\
\text { in Eq.2 } \\
U_{0}\left(U_{1}^{2}+U_{2}^{2}\right. \\
\left.+U_{4}^{2}\right)\end{array}$ & $\begin{array}{l}\text { Max } \\
\mathrm{D} 2 \\
(\mathrm{~m})\end{array}$ & $\begin{array}{l}\text { Max } \\
\mathrm{D} 4 \\
(\mathrm{~m})\end{array}$ \\
\hline 0 & 0.10 & 0.10 & 0.08 & 0.04 & 0.00 & 0.00 & 0.38 & 0.02 \\
\hline 5 & 0.14 & 0.14 & 0.45 & 0.09 & 0.03 & 0.03 & 0.36 & 0.03 \\
\hline $\mathbf{1 0}$ & $\mathbf{0 . 2 3}$ & $\mathbf{0 . 1 1}$ & $\mathbf{0 . 4 0}$ & $\mathbf{0 . 0 6}$ & $\mathbf{0 . 0 4}$ & $\mathbf{0 . 0 4}$ & $\mathbf{0 . 3 3}$ & $\mathbf{0 . 0 4}$ \\
\hline 20 & 0.42 & 0.07 & 0.21 & 0.04 & 0.02 & 0.02 & 0.27 & 0.03 \\
\hline 40 & 0.70 & 0.03 & 0.09 & 0.01 & 0.01 & 0.01 & 0.15 & 0.02 \\
\hline 60 & 0.86 & 0.02 & 0.04 & 0.01 & 0.00 & 0.00 & 0.09 & 0.01 \\
\hline 125 & 0.96 & 0.01 & 0.01 & 0.00 & 0.00 & 0.00 & 0.02 & 0.00 \\
\hline
\end{tabular}

Increasing river discharge increases the residual velocity and reduces the tidal velocity components (Table 5) at R2.Thus, the Q10 scenario generates maximum $U_{0}\left(U_{1}^{2}+U_{2}^{2}+U_{4}^{2}\right)$ in Equation 2 and the maximum friction coefficient for D4.Table 5 shows that there is an optimum balance in the Q10 scenario at R2 between residual velocity and tidal velocity components, which dictates the generation or dissipation of the D4 tide. Similarly, an optimum balance between residual velocity and tidal velocity components is 
also found at R3 and R5 for the Q20 and Q40 scenarios, respectively. However, at R4, maximum D4 occurs in the Q40 scenario whereas the Q20 scenario generates maximum $U_{0}\left(U_{1}^{2}+U_{2}^{2}+U_{4}^{2}\right)$. This apparent contradiction is caused by rapidly changing geometry of the river (both in width and depth) at that station. According to Godin (1991), the convective term and the continuity term in the equations of motion can also create high-frequency harmonics whenever the river geometry varies rapidly over a short distance. In conclusion, optimal balance between river velocity and velocity of tidal components upstream of the estuary mouth, which is caused by a critical level of river discharge, modulates the generation and dissipation of the D4 tide. For river discharge higher than this critical discharge value, tidal velocity components are negligible compared to the residual velocity $\left(\mathrm{U}_{2} \ll \mathrm{U}_{0}\right)$ and dissipates both D2 and D4 tides rapidly.

The rapid dissipation of quarterdiurnal tides due to friction in the upper estuary was also observed in the St. Lawrence estuary by Matte et al. (2014). They found that the M4 tide is damped more rapidly by discharge and the resulting friction than it is generated from the nonlinear interactions between M2 and M4 beyond $186 \mathrm{~km}$ from the estuary mouth. Our findings demonstrate that the processes also occur in the complex geometry of the GBMD.

\section{Conclusions}

This study investigates the influence of river discharge on tide variations along the Ganges-Brahmaputra-Meghna Delta, which is fed by a monsoonal catchment. The Delft3d model is configured and applied to the GBMD to reproduce spatial and temporal water level and tidal properties variability for different river discharge conditions. The model results show good agreement with the observed water levels $\left(\mathrm{R}^{2}>0.92\right)$ and tidal range across the study area for an average flood year condition (2000) in spite of uncertainties associated with the bathymetry and time of data availability. In particular, the modeled tidal ranges have better agreement in the upper estuary compared to previous studies in the GBMD (e.g., Bricheno et al., 2016; and Tazkia et al., 2017).

River discharge plays a key role in water level and tide propagation in the GBMD. The strong monsoon river discharge results in higher water levels in the upper estuary compared to the estuary mouth. Near the upstream limit of tidal propagation at $205 \mathrm{~km}$ from the estuary mouth, the mean water level varies seasonally between $2 \mathrm{~m}$ (dry season) and $10 \mathrm{~m}$ (monsoon season). The tidal ranges also fluctuate with the seasonal river discharge along the estuary; the decrease in tidal range has a close relationship with increasing river discharge beyond $115 \mathrm{~km}$ from the estuary mouth. The tidal ranges at the station $30 \mathrm{~km}$ from the estuary mouth, are $0.57 \mathrm{~m}$ and $0.27 \mathrm{~m}$ lower during the wet season $\left(60,000 \mathrm{~m}^{3} \mathrm{~s}^{-1}\right)$ than during the dry season $\left(10,000 \mathrm{~m}^{3} \mathrm{~s}^{-1}\right)$ for neap and spring tides, respectively. The residual water level slope and tidal damping increase with river discharge beyond $100 \mathrm{~km}$ from the estuary mouth, which demonstrates the influence of river discharge on tides.

The study shows that the GBMD is a mixed tidal regime where D2 tide is dominant along the delta up to $150 \mathrm{~km}$ from the estuary mouth. The D1 tide varies between 0 to $0.4 \mathrm{~m}$ along the study area. The D2 tide travels up to $205 \mathrm{~km}$ and $130 \mathrm{~km}$ from the estuary mouth during the dry and wet season, respectively. The MSF tide travels further into the upper river (beyond $205 \mathrm{~km}$ ) compared to the D2 tide, because higher frequency tides are dampened faster by river discharge and non-linear interactions. The increase of the river discharge 
increases the generation and amplification of the MSF tide beyond $100 \mathrm{~km}$, whereas the other tidal components are reduced to nearly zero.

Results of a non-stationary harmonic analysis of the modeled water levels show the sizeable seasonal variation of D2 and D4 tides with the changing river discharge along the estuary. During the monsoon season D2 is reduced to approximately $0.19 \mathrm{~m}$ in the middle of the GBMD (102 km from the estuary mouth) whereas, in the dry season, it increases to 0.94 $\mathrm{m}$. Similar seasonal variation is also found for the D4 tide. Beyond the middle of the GBMD (100 km from the estuary mouth), seasonal variations of the D2 and D4 tides with changing river discharge demonstrate the mechanism of modulating tides through total friction generated from combined effects of river discharge and tides. At R2 where tides are nearly extinct $(\mathrm{D} 2<0.20 \mathrm{~m}$ ) in an average year condition, different idealized river discharge scenarios illustrate the presence of a balance between the dissipation of $\mathrm{D} 2$ and the generation of D4 tide.

The total friction generated by a specific river discharge scenario $\left(<20,000 \mathrm{~m}^{3} \mathrm{~s}^{-1}\right)$ results in a higher D4 tide compared to other (lower or higher) river discharge scenarios at the upper GBMD. The decomposition of the frictional term shows that friction related to rivertide interaction plays an essential role in the D4 tide generation with a maximum generated friction producing maximum D4 amplitude in the upper GBMD. The generation of the D4 tide from the river-tide interaction depends on the contribution from the residual and principal tide velocity components. There is an optimum balance between river discharge (the critical discharge) and energy transfer from the D2 tide that controls the local generation or dissipation of the D4 tide in the upper estuary. The optimum balance produces maximum friction related to river-tide interaction that generates maximum amplitude of D4 tide. River discharge beyond the critical discharge threshold rapidly dissipates both D2 and D4 tides rather than generating the $\mathrm{D} 4$ tide.

Finally, the results presented in this study, particularly the influence of strong monsoon river discharge on tides, are important for understanding, modeling, and manage complex estuarine systems like the Ganges-Brahmaputra-Meghna Delta. The established model setup can be further applied to investigate estuarine processes such as flood risk assessment, storm surges, and sediment transport dynamics.

\section{Acknowledgment}

This is publication No. 71 of the Sino-Australian Research Consortium for Coastal Management (previously the Sino-Australian Research Centre for Coastal Management). The authors acknowledge the continuous support from Professor Munsur Rahman, Institute of Water of Flood Management, BUET by sharing the bathymetric survey data, and water level data from Bangladesh Water Development Board and Bangladesh Inland Water Transport Authority.

The cross sections shared by the following two consortium projects are also gratefully acknowledged:

1) Assessing health, livelihoods, ecosystem services and poverty alleviation in populous deltas', project number NE-J002755-1, was funded with support from the Ecosystem Services for Poverty Alleviation (ESPA) program. The ESPA program is funded by the 
Department for International Development (DFID), the Economic and Social Research Council (ESRC) and the Natural Environment Research Council (NERC).

2) Deltas, Vulnerability and Climate Change: Migration and Adaptation project (IDRC 107642) under the Collaborative Adaptation Research Initiative in Africa and Asia (CARIAA) program with financial support from the Department for International Development, UK Government (DFID) and the International Development Research Centre (IDRC), Canada.

The model results and other supporting information can be found at https://doi.org/10.26190/p5c8-te58.

\section{Appendix}

\section{A. Complex demodulation method}

The complex demodulation method can be used to compute time varying tidal constituents. Details of the method are described by Jalón-Rojas et al. (2018) as below:

Complex Demodulation theory assumes that the time series $\mathrm{X}(\mathrm{t})$ is composed of a nearly periodic signal with frequency $\sigma$ and a non-periodic signal $\mathrm{Z}(\mathrm{t})$ given by:

$$
X(t)=A(t) \cos (\sigma t+\phi(t))+Z(t)
$$

Here, $\mathrm{A}$ and $\phi$ denote tidal amplitude and phase, respectively. Tidal component of frequency influences the nearly periodic signal.

The nearly periodic signal is influenced by the tidal component of frequency $\sigma\left(2 \pi / 12.48 \mathrm{~h}^{-1}\right.$ for $\mathrm{D}_{2}$ or $2 \pi / 6.24 \mathrm{~h}^{-1}$ for $\mathrm{D}_{4}$ ) with amplitude $\mathrm{A}$ and phase $\phi$. The amplitude and phase are allowed to vary with time but slowly compared to the frequency $\sigma$. These parameters are estimated in three steps:

a) The original time series is multiplied by $\mathrm{e}^{-\mathrm{iot}}$ in order to shift the frequency of interest to zero:

$$
\mathrm{Y}(\mathrm{t})=\mathrm{X}(\mathrm{t}) \mathrm{e}^{-\mathrm{i} \sigma \mathrm{t}}=\frac{\mathrm{A}(t)}{2} \mathrm{e}^{-\mathrm{i} \phi(t)}+\frac{\mathrm{A}(t)}{2} \mathrm{e}^{-\mathrm{i}(2 \sigma t+\phi(t))}+Z(\mathrm{t}) \mathrm{e}^{-\mathrm{i} \sigma \mathrm{t}}
$$

b) $\mathrm{Y}(\mathrm{t})$ is then low-pass filtered to remove frequencies at or above $\sigma$, i.e. the terms $\frac{\mathrm{A}(t)}{2} \mathrm{e}^{-\mathrm{i}(2 \sigma t+\phi(t))}+Z(\mathrm{t}) \mathrm{e}^{-\mathrm{i} \sigma \mathrm{t}}$ are removed to give

$$
\mathrm{Y}^{\prime}(\mathrm{t})=\frac{\mathrm{A}^{\prime}(t)}{2} \mathrm{e}^{-\mathrm{i} \phi^{\prime}(t)}
$$

c) The corresponding $A^{\prime}(t)$ and $\phi^{\prime}(t)$ are calculated from the Inverse Fourier Transform of the filtered spectrum $Y^{\prime}(t)$ :

$$
\mathrm{A}^{\prime}(\mathrm{t})=2\left|Y^{\prime}\right|=2\left(\operatorname{Re}\left(Y^{\prime}\right)^{2}+\operatorname{Im}\left(Y^{\prime}\right)^{2}\right)^{1 / 2}
$$




$$
\phi^{\prime}(\mathrm{t})=\operatorname{specific}\left(\frac{\operatorname{Re}\left(Y^{\prime}\right)}{\operatorname{Im}\left(Y^{\prime}\right)}\right)
$$

The estimated $\mathrm{A}^{\prime}(\mathrm{t})$ and $\phi^{\prime}(\mathrm{t})$ are used as the amplitude and phase in this study.

\section{B. The stationary harmonic analysis result}
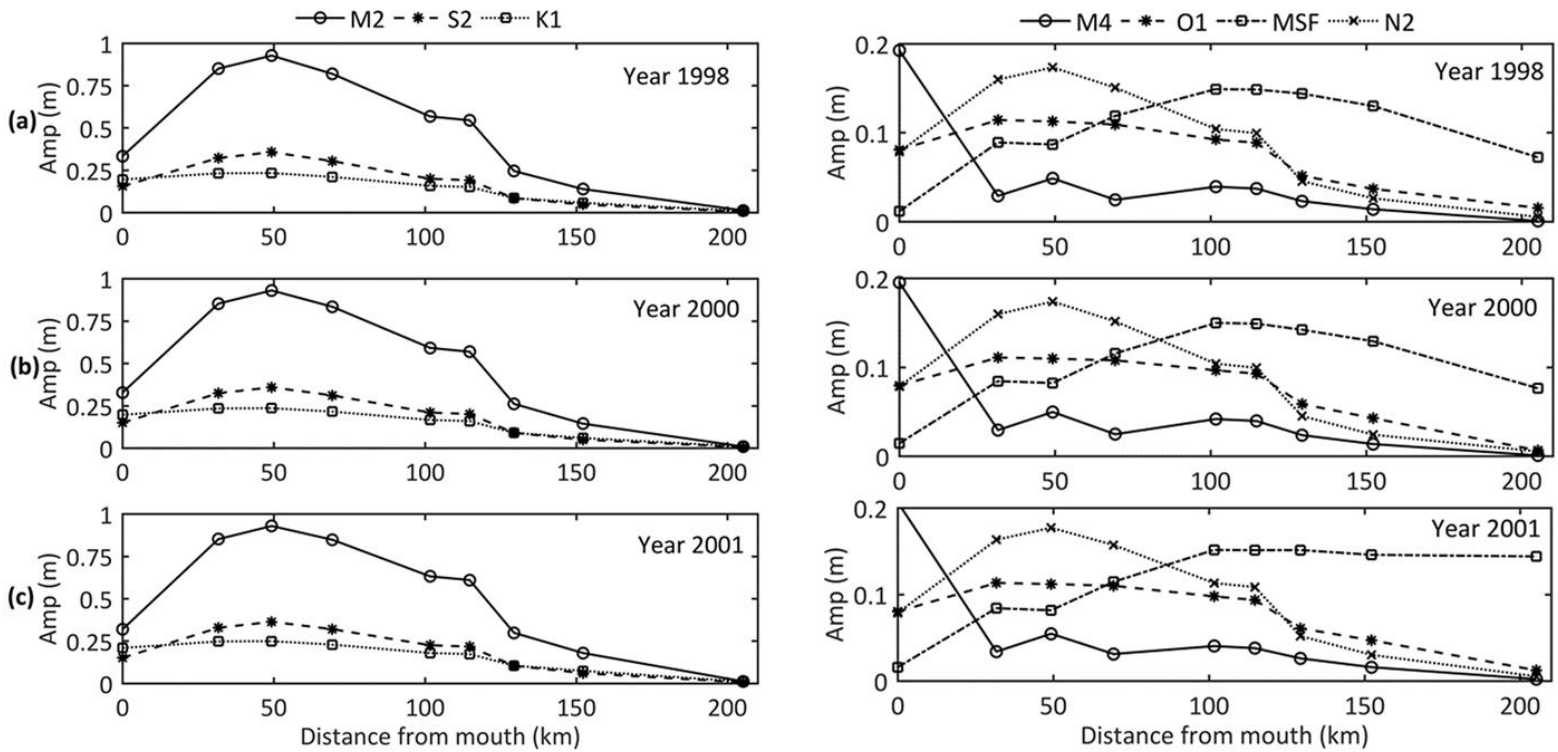

Figure B.1. Spatial variations of tidal amplitudes for: (a) 1998; (b) 2000; and (c) 2001 from the stationary harmonic analysis.

\section{References}

Allison, M. a. (1998). Geologic framework and environmental status of the GangesBrahmaputra delta. Journal of Coastal Research, 14(3), 826-836.

https://doi.org/10.1017/CBO9781107415324.004

Bloomfield, P. (2004). Fourier Analysis of Time Series: An Introduction. Wiley. Retrieved from https://books.google.com.au/books?id=zQsupRg5rrAC

Bricheno, L. M., Wolf, J., \& Islam, S. (2016). Tidal intrusion within a mega delta: An unstructured grid modelling approach. Estuarine, Coastal and Shelf Science, 182, 12 26. https://doi.org/10.1016/j.ecss.2016.09.014

Bricheno, L., \& Wolf, J. (2018). Modelling Tidal River Salinity in Coastal Bangladesh. In R. J. Nicholls, C. W. Hutton, W. N. Adger, S. E. Hanson, M. M. Rahman, \& M. Salehin (Eds.), Ecosystem Services for Well-Being in Deltas: Integrated Assessment for Policy Analysis (pp. 315-332). Cham: Springer International Publishing. https://doi.org/10.1007/978-3-319-71093-8_17

Buschman, F. A., Hoitink, A. J. F., Van Der Vegt, M., \& Hoekstra, P. (2009). Subtidal water level variation controlled by river flow and tides. Water Resources Research, 45(10), $1-$ 12. https://doi.org/10.1029/2009WR008167 
BWDB. (2012). Annual Report: Flood Forcasting and Warning Centre, Processing and Flood Forecasting Circle. Dhaka, Bangladesh.

Cai, H., Savenije, H. H. G., \& Toffolon, M. (2014). Linking the river to the estuary: Influence of river discharge on tidal damping. Hydrology and Earth System Sciences, 18(1), 287304. https://doi.org/10.5194/hess-18-287-2014

Cai, Huayang, Savenije, H., Garel, E., Zhang, X., Guo, L., Zhang, M., ... Yang, Q. (2019). Seasonal behaviour of tidal damping and residual water level slope in the Yangtze River estuary: identifying the critical position and river discharge for maximum tidal damping. Hydrology and Earth System Sciences, 23, 2779-2794. https://doi.org/10.5194/hess-232779-2019

Dalrymple, R. W., \& Choi, K. (2007). Morphologic and facies trends through the fluvialmarine transition in tide-dominated depositional systems: A schematic framework for environmental and sequence-stratigraphic interpretation. Earth-Science Reviews, 81(34), 135-174. https://doi.org/10.1016/j.earscirev.2006.10.002

Deltares, D. (2014). Delft3D-FLOW Simulation of Multi-Dimensional Hydrodynamic Flows and Transport Phenomena Including Sediments, User Manual. Deltares Delft, The Netherlands.

FAO. (2016). AQUASTAT - FAO's Information System on Water and Agriculture. Retrieved May 4, 2018, from http://www.fao.org/nr/water/aquastat/countries_regions/profile_segments/gbmWR_eng.stm

Gallo, M., \& Vinzon, S. (2005). Generation of overtides and compound tides in Amazon estuary. Ocean Dynamics, 55(5), 441-448. https://doi.org/10.1007/s10236-005-0003-8

Godin, G. (1991). Compact approximations to the bottom friction term, for the study of tides propagating in channels. Continental Shelf Research, 11(7), 579-589. https://doi.org/10.1016/0278-4343(91)90013-V

Godin, G. (1999). The Propagation of Tides up Rivers With Special Considerations on the Upper Saint Lawrence River. Estuarine, Coastal and Shelf Science, 48(3), 307-324. https://doi.org/https://doi.org/10.1006/ecss.1998.0422

Godin, Gabriel, \& Martinez, A. (1994). Numerical experiments to investigate the effects of quadratic friction on the propagation of tides in a channel. Continental Shelf Research, 14(7), 723-748. https://doi.org/https://doi.org/10.1016/0278-4343(94)90070-1

Google. (n.d.). No Title. Retrieved April 3, 2020, from https://www.google.com/maps/@22.70103,90.80391,185671m/data=!3m1!1e3

Guo, L., Wegen, M. van der, Jay, D. A., Matte, P., Wang, Z. B., Roelvink, D., \& He, Q. (2015). River-tide dynamics: Exploration of nonstationary and nonlinear tidal behavior in the Yangtze River estuary. Journal of Geophysical Research C: Oceans, 120, 34993521. https://doi.org/10.1002/2014JC010491.Received

Haque, A., \& Nicholls, R. J. (2018). Floods and the Ganges-Brahmaputra-Meghna Delta. In Ecosystem Services for Well-Being in Deltas (pp. 147-159). Cham: Springer 
International Publishing. https://doi.org/10.1007/978-3-319-71093-8_8

Jalón-Rojas, I., Sottolichio, A., Hanquiez, V., Fort, A., \& Schmidt, S. (2018). To What Extent Multidecadal Changes in Morphology and Fluvial Discharge Impact Tide in a Convergent (Turbid) Tidal River. Journal of Geophysical Research: Oceans, 32413258. https://doi.org/10.1002/2017JC013466

Krien, Y., Mayet, C., Testut, L., Durand, F., Tazkia, A. R., Islam, A. K. M. S., ... Ballu, V. (2016). Improved Bathymetric Dataset and Tidal Model for the Northern Bay of Bengal. Marine Geodesy, 39(6), 422-438. https://doi.org/10.1080/01490419.2016.1227405

LeBlond, P. H. (1978). On tidal propagation in shallow rivers. Journal of Geophysical Research: Oceans, 83(C9), 4717-4721. https://doi.org/10.1029/JC083iC09p04717

Matte, P, Secretan, Y., \& Morin, J. (2017). Hydrodynamic modeling of the St. Lawrence fluvial estuary. II: Reproduction of spatial and temporal patterns. Journal of Waterway, Port, Coastal and Ocean Engineering, 143(5), <xocs:firstpage xmlns:xocs=""/>. https://doi.org/10.1061/(ASCE)WW.1943-5460.0000394

Matte, Pascal, Secretan, Y., \& Morin, J. (2014). Temporal and spatial variability of tidalfluvial dynamics in the St. Lawrence fluvial estuary: An application of nonstationary tidal harmonic analysis. Journal of Geophysical Research: Oceans, 119(9), 5724-5744. https://doi.org/10.1002/2014JC009791

Ogston, A. S., Allison, M. A., Mclachlan, R. L., Nowacki, D. J., \& Stephens, J. D. (2017). How tidal processes impact the transfer of sediment from source to sink: Mekong River collaborative studies. Oceanography. https://doi.org/10.5670/oceanog.2017.311

Pawlowicz, R., Beardsley, B., \& Lentz, S. (2002). Classical tidal harmonic analysis including error estimates in MATLAB using TDE. Computers and Geosciences, 28(8), 929-937. https://doi.org/10.1016/S0098-3004(02)00013-4

Pethick, J., \& Orford, J. D. (2013). Rapid rise in effective sea-level in southwest Bangladesh: Its causes and contemporary rates. Global and Planetary Change, 111, 237-245. https://doi.org/10.1016/J.GLOPLACHA.2013.09.019

Rogers, K. G., \& Goodbred, S. L. (2014). The Sundarbans and Bengal Delta: The World's Largest Tidal Mangrove and Delta System. In V. S. Kale (Ed.), Landscapes and Landforms of India (pp. 181-187). Springer. https://doi.org/10.1007/978-94-017-8029$2 \_18$

Rose, L., \& Bhaskaran, P. K. (2017). Tidal propagation and its non-linear characteristics in the Head Bay of Bengal. Estuarine, Coastal and Shelf Science, 188, 181-198. https://doi.org/10.1016/J.ECSS.2017.02.024

Savenije, H. H. G., Toffolon, M., Haas, J., \& Veling, E. J. M. (2008). Analytical description of tidal dynamics in convergent estuaries. Journal of Geophysical Research: Oceans, 113(C10), n/a-n/a. https://doi.org/10.1029/2007JC004408

Snead, R. E. (2010). Bangladesh. In E. C. F. Bird (Ed.), Encyclopedia of the World's Coastal Landforms (pp. 1077-1080). Dordrecht: Springer Netherlands. https://doi.org/10.1007/978-1-4020-8639-7_201 
Song, D., Wang, X. H., Zhu, X., \& Bao, X. (2013). Modeling studies of the far-field effects of tidal flat reclamation on tidal dynamics in the East China Seas. Estuarine, Coastal and Shelf Science, 133, 147-160.

https://doi.org/https://doi.org/10.1016/j.ecss.2013.08.023

Tazkia, A. R., Krien, Y., Durand, F., Testut, L., Islam, A. S., Papa, F., \& Bertin, X. (2017). Seasonal modulation of M2 tide in the Northern Bay of Bengal. Continental Shelf Research, 137, 154-162. https://doi.org/10.1016/J.CSR.2016.12.008

Wang, Z., Winterwerp, J., \& He, Q. (2014). Interaction between suspended sediment and tidal amplification in the Guadalquivir Estuary. Theoretical, Computational and Observational Oceanography, 64(10), 1487-1498. https://doi.org/10.1007/s10236-0140758-x
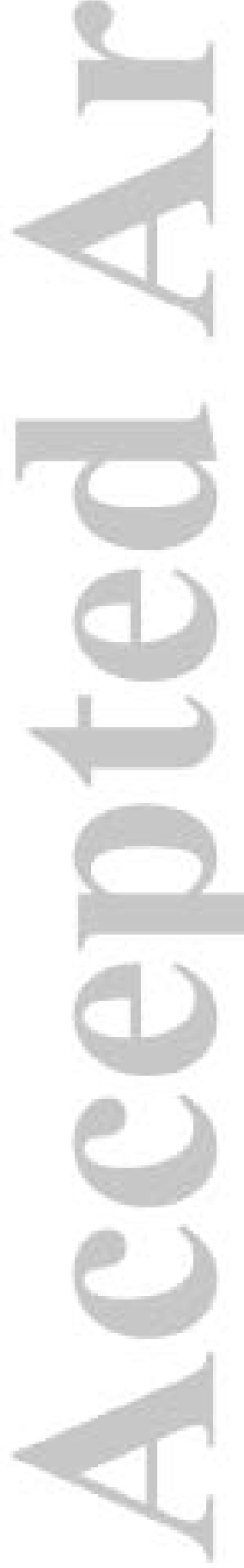